\title{
ON THE TEMPERATURE
}

\author{
OF \\ PHTHISIS PULMONALIS,
}

AND ON THF

VARIOUS CONDITIONS INFLUENCING IT.

$\mathbf{B Y}$

C. THEODORE WILLIAMS, M.A., M.D. Oxon., F.R.C.P., PHYSICIAN TO THR HOSPITAL POR CONSUMPTION AND DISEASES OF THE CHEST, BROMPTON.

(Received December 10th, 1874-Read January 26th, 1875.) :

The value of the thermometer in the clinical study of phthisis, whether as a means of diagnosis from other diseases, or between forms of the same malady, or, again, as a measure of the degree of fever and constitutional infection, is a subject which has been largely discussed both here and on the Continent, and the very various and often discordant views held by different observers lead one to believe that the true temperature-course of phthisis is yet an unsolved problem.

Jochmann ${ }^{1}$ appears in 1853 to have arrived at a more elaborate classification of the temperatures in consumption than any who followed him. He enumerates three types, and to each of these he appends two or more variations; in the case of one type even these variations are subdivided again, and the impression derived from a perusal of this

1 'Beobachtungen über die Körper-Wärme in chronischen fieberhaften Krankheiten.’ 
careful arrangement is that the exceptions considerably outnumber the rules, and but little comfort is conveyed by Jochmann's further statement that all these types may alternate with another in a single case, or by Dr. Wilson Fox's objection that acute tuberculosis is not included in Jochmann's tables.

Dr. Sydney Ringer, in the first edition of his ' Temperature in Phthisis,' lays down some striking propositions deduced from twenty-four cases; among these we find "that a daily elevation of temperature probably takes place in all cases in which a deposition of tubercle is taking place in any organ;" also "that the temperature may be taken as a measure of the amount of tuberculosis and tuberculization, and fluctuations in the former indicate corresponding fluctuations in the severity of the disease." Dr. Ringer insists, too, that in many instances the temperature is of more value than physical signs and symptoms for the diagnosis of phthisis.

In his second edition these views are maintained with some modification, and whilst admitting that tuberculization or catarrhal pneumonia may advance so slowly as to cause little or no elevation of temperature, he states that where this symptom is absent we may conclude that the progress of the disease is almost insignificant.

All workers on the subject must feel greatly indebted to Dr. Ringer for his additions to our knowledge, and for the many valuable suggestions which he has made for future inquiry; and if the cases I am about to bring forward have led me to differ from him in some respects, in many others they have, from larger data than his own, abundantly confirmed his conclusions.

Niemeyer ${ }^{1}$ held that the thermometer enabled us to distinguish between the tuberculous and pneumonic forms of phthisis, because of the greater remissions displayed in the charts of the former, while on the other hand several observers, including Wunderlich and Lebert, maintain that no thermometrical distinction is possible between the anatomical forms of the disease. 
Lebert, 1 in a laborious treatise based on observations on several patients, extending over many years, gives a number of careful results, and states his conclusions in the small number of fifty-one propositions! many of which, when carefully compared, are found to contradict one another, and his most important one, viz. " that individual idiosyncrasy influences the temperature course more than the form, localisations, or phase of the disease," does not add to the lucidity of his deductions or afford a very safe ground for classification.

Dr. Wilson Fox has made the most recent contribution to the subject in the form of a lengthy and painstaking paper in the fifty-sixth volume of the 'Medico-Chirurgical Transactions.' His observations were made twice a day, morning and evening, on eighty in-patients at University College Hospital, the cases being " instances of more or less distinctly advanced disease admitted to a general hospital on account of its acuteness, its extent, or recent aggravation." Dr. Fox acknowledges that they represent severe cases only, and " thus afford no information respecting the earlier stages, or the periods of comparative quiescence."

Dr. Fox's cases are divided into-1st, fatal, including acute tuberculosis, acute pneumonic phthisis, and chronic phthisis ; 2nd, non-fatal, subdivided into high and low temperatures.

Both these classes seem to me based on somewhat arbitrary principles, as the class in which a patient would be :placed depended on the part of his career which he spent in the hospital; also the division into high and low temperatures seems to involve a petitio principii, as it ought to be the author's object to arrive at a clinical or pathological basis of thermal classification, and not to prejudge the matter by dividing into classes according to the temperature. After a minute analysis of the temperatures in all these classes-in which, by-the-bye, little or no note is taken of the physical signs, and the extent of consolidation or excavation-he comes to no very definite conclusions beyond agreeing with Lebert, "that difference of temperature depends either on the con1 'Deutsch. Archiv Klin. Med.,' Nov., 1872. 
stitutional peculiarity of individual patients, or on the varieties in the pyrogenic effects of the changes in the lungs which require further elucidation."

A careful survey of the above authorities impressed me with the conviction that the observations hitherto made have been carried out in the routine fashion generally in vogue in hospitals for exanthematous fevers, surgical inflammations, and the like, and that sufficient notice has not been taken of the peculiarities of the special disease under consideration.

By the majority of observers the temperature was taken only twice a day, morning and night, even the hours not being always specified, and the changes in the intermediate period remaining an untold tale, though one authority speaks of remissions from morning to evening, and the reverse, as if the thermometer stood still and the course of events between these periods was unchequered by variations.

It is obvious that many and great changes may take place between these two periods, and observations may show a case to be pyrexial in the afternoon, whose morning and night records are perfectly normal, and, indeed, Kuchenmeister ${ }^{1}$ maintains that the maximum exacerbation occurs between noon and 2 p.m., and that a lowering follows till 5 p.m., when a second exacerbation occurs much inferior in intensity to the midday one. No note, moreover, is found in any of the above authorities of the thermometric changes occurring during the hours of rest, or the influence of sleep on them, and it would naturally occur that this would be the proper period to mark the commencement of pyrexia, or the subsidence of the same. ${ }^{2}$

A second great objection presents itself in the fact that the observations have been made on the disease as a whole, and not on its individual stages and developments. Surely some regard should be had to physical signs, and obser-

1 ' Kaltes Wasser,' p. 220.

2 Dr. Wilson Fox admits that on this account his results have only an approximate value, and $I$ understand that both he and Dr. Ringer are now modifying their plan, and taking observations oftener. Some of Dr. Ringer's original cases were taken three or four times daily. 
vations taken when these indicated the formation of tubercle should not be jumbled up with others recording the progress of a discharging cavity. Or, again, the records of intercurrent inflammations should not be entirely confused with others of progressive excavation. In the above instances the formation of pus should be duly taken into consideration, as its absence or presence may entirely modify the temperature course.

The unusual opportunities afforded by my position as physician to the Hospital for Consumption and Diseases of the Chest, Brompton, where I have from fifty to sixty beds under my charge, enabled me to institute a more complete series of observations than has ever been before attempted; for within these wards may be found at the same time instances of all stages and degrees of consumptive disease subjected to the same hygienic conditions.

One great advantage this institution offers for thermometric investigations is that by means of the heating and ventilating apparatus an equable temperature of from $60^{\circ}$ to $63^{\circ}$ Fahr. is maintained day and night, and in order to exclude the effects of recent colds, fatigue, inanition, and other disturbing elements, it has been my practice not to commence observations until the patients have been at least a week in the hospital, and therefore placed under circumstances more likely to ensure accurate results.

The number of patients furnishing the results was 111; 66 males, 45 females; nearly all adults. The ages being from 13 to 49 ; the average of the males being 26 , and of the females 27 .

The greater number of the observations were made in the axilla, the thermometers being left in about ten minutes. Mouth temperatures were taken in a few cases, and in one a double record of both mouth and axilla heat was made with a view of checking the general results and of testing the accuracy of other observers on this point.

The thermometers used were principally those of $\mathrm{Mr}$. Hawkesley, and were found, on testing, to be very accurate; a few furnished by other well-known makers, as Mr. Casella, 
Messrs. Harvey and Reynolds, of Leeds, and Messrs. Meyer and Melzer, were also in use.

The observers were, for the most part, the various gentlemen who have held the offices of assistant resident medical officer or of clinical assistant at the Brompton Hospital during the last four years, viz. Messrs. Bartlett, Parry, McKinlay, Williams, Hartley, Peacey, Crocker, Boys, Murrell, Bernays, and Kelly, superintended and directed by myself; and I take this opportunity of gratefully acknowledging the careful and steady manner in which the observations were made and my directions carried out, involving, as may be seen hereafter, considerable sacrifices of time and comfort. It was only by infusing into my companions and myself a spirit of fervid scientific enthusiasm to attempt the solution of the oft-vexed problem of the temperature in phthisis that we succeeded in enduring the irksomeness entailed by so long and tedious a series of observations.

The patients were, for the most part, under my own care, but as my colleagues kindly allowed me to make use of any of their cases of interest bearing on the subject, I did not hesitate to avail myself of special opportunities occurring in their wards.

The hours of observation at first selected were 8 a.m., 11 a.m., 2 p.m., 5 p.m., and 8 p.m., and in none of the 111 cases were the temperatures less often taken than at these five periods.

The number of days during which this record was carried on varied from seven to thirty, excepting three cases of low temperature, where days registered did not reach seven.

In the course of these observations so much irregularity was noted that $I$ deemed it necessary to investigate the temperatures of intermediate hours, and, therefore, supplementary observations were taken at 10 a.m., at 3, 6, 7, 9, 10 , and 12 p.m. in many of the cases, and in this way 4226 records were collected. Thus we arrived at some definite conclusious with respect to the day temperature of phthisis; but to test these conclusions especially with regard to cavity cases, hourly observations were taken in one instance, in a 
well-marked third-stage patient, from 8 a.m. to 8 p.m., thirteen times a day for a period of a fortnight, by $\mathbf{M r}$. McKinlay (see Plate II).

Our next step was to investigate the temperatures of the night and of the early morning, and to compare these with the day records, and for this purpose I selected twelve of the above-mentioned patients in whom the different stages of the disease were well marked, and in all of these, except one, an hourly record was carried out for twenty-four hours; in that one the twelve night hours only were noted.

In two of these cases, in order to confirm the first thermic cycle, a second series of hourly temperatures for a day and night were recorded.

At the same time careful notes were taken of all phenomena which could possibly influence or be influenced by the temperature, e.g. the state of the pulse, respiration, skin, bowels, the quantity of urine passed, the hours of meals and the food taken, the administration of drugs, the amount of sleep, and the temperature of the ward.

This laborious inquiry was carried out by my kind assistants, Messrs. McKinlay, Williams, Parry, Boys, Murrell, and by myself. A specimen of our mode of record is exhibited.

Charles R-, æt. 17.

\begin{tabular}{|c|c|c|c|c|c|c|c|c|}
\hline Date. & Hour. & Temp. & Pulse. & Resp & Meals. & $\begin{array}{c}\text { Temp. } \\
\text { of } \\
\text { ward. }\end{array}$ & Notes. & Physical signs. \\
\hline June 17 & 9 a.m. & $103 \cdot 2^{\circ}$ & 104 & 36 & $\begin{array}{c}\text { Breakf'st, } \\
\text { egg, } \\
\text { bread, } \\
\text { butter, } \\
\text { and cocoa } \\
\text {... }\end{array}$ & $64^{\circ}$ & $\begin{array}{c}\text { Awake ; skin } \\
\text { moist; urine } \\
\text { plentiful and } \\
\text { normal } \\
\ldots \\
\ldots\end{array}$ & $\begin{array}{l}\text { Right. - Flat- } \\
\text { tening; crepi- } \\
\text { tation, whole } \\
\text { front, most } \\
\text { marked and } \\
\text { coarse at base. } \\
\text { Left. - Very } \\
\text { coarse crepi- } \\
\text { tation, lower } \\
\text { half; cavern- } \\
\text { ous sounds } \\
\text { between fifth } \\
\text { and sixth ribs. }\end{array}$ \\
\hline
\end{tabular}


An account of the principles which have guided my arrangement of cases must now be given, and I need hardly say that my object has been to simplify these as much as possible.

Any strict classification of cases of consumption is attended with great difficulties, and cannot be carried out without making arbitrary distinctions which neither clinical nor pathological observations support. Whilst fully recognising the different parts played by the inflammatory and infective processes in phthisis, I have always maintained that the various forms are mere groupings of the same terrible disease, and that between these groups every gradation of link, pathological and clinical, can be found.

Now that we have cleared our eyes from the mists of Niemeyerian doctrines, and.contemplate phthisis as it exists ordinarily and not exceptionally, the unity of the disease appears as well founded as it did before the cloud of German speculation obscured the horizon.

The most valuable result of the debate on Tubercle at the Pathological Society has been to establish a distinct anatomical basis for most forms of phthisis, and to demonstrate the identity of the grey granulation, the soft granulation, and the various caseous changes by the presence of the smallcelled lymphoid growth; and if we owed Dr. Wilson Fox no other debt of gratitude, this alone of having settled the tubercle question on a basis so satisfactory to future workers would entitle him to our warmest thanks. ${ }^{1}$

The cases on which the temperature observations were made were of the ordinary type of consumptive patients as admitted into the Brompton Hospital, and except that some may be called acute and others chronic cases, it would be difficult to separate them abruptly.

They were no instances of rare forms of tuberculosis requiring microscopical investigation for its detection, but

1 At the same time we must not forget the considerable part played by exudation in many acute cases of phthisis. Dr. C. J. B. Williams has long held this to be the case, and recently Dr. T. H. Green has stated that the small-celled growth is absent, and exudation and epithelial proliferation are the chief characteristics of many cases of acute phthisis (not tuberculosis). 
rather examples of that common and deadly disease familiar to us all, and fatal yearly to one eighth of our population.

One hundred and four of the patients under observation have been arranged in five classes, according to the stage of the disease and the activity of its progress : 1st stage, active, 26 cases ; 1st stage, quiescent, 5 cases. 2nd stage, 10 cases. 3rd stage, active, 43 cases; 3rd stage, quiescent, 20 cases.

This arrangement is, of course, almost entirely based on physical signs, and in the 10 cases in which post-mortem examinations were made the diagnosis was amply confirmed.

As will be seen, the relations of temperature to the formation of tubercle, to softening and excavation, and again to continued ulceration of the lungs, are all carefully worked out.

It is because physical signs are our chief means of detecting the occurrence of the above phenomena that I have made them the basis of my divisions, but as far as possiblefull regard has been paid to clinical and pathological features, always excepting the temperature itself, as it was my object to classify, not it, but its accompanying conditions, and thus to deduce its factors.

In the 104 patients both lungs were attacked in 66 (almost two thirds), one lung in 38 (about one third), the right alone in 17, and the left alone in 21 . Of the 31 . in the first stage 16 had both lungs affected, and 8 a single one; of the 10 second-stage cases 5 had both lungs involved, and 5 one lung only; and of the 63 in the third stage $45 \mathrm{had}$ both lungs attacked, of which 10 had double cavities.

We will now proceed to consider each class of cases and the temperature prevalent in them, and first let us take Class I, first stage, active (Plate III, fig. 1).

The physical signs generally noticed here were (1) those indicating the commencement of disease in the lung hitherto free, or (2) the extension of disease in a lung part of which was already consolidated; and great care has been taken to exclude all cases where anything besides consolidation or scattered tubercle was suspected. The crepitation was generally of a fine description, and, as regards locality, often 
scattered over the upper lobes. That it did not pass into the coarse crepitation of a croaking character typical of softening was confirmed by subsequent observation in each instance.

The following instance of the development of disease and its accompanying thermal phenomena will help to illustrate the features of this class :

CASE 1.-W. G. W-, æt. 14, was admitted into Wallace Ward, April 29th, 1873.

History. - Father died of consumption. Sister suffers from chest disease.

A week after Christmas, was attacked with giddiness and pain in right chest, and night sweats; three days after he complained of cough with scanty expectoration, which has continued since; has not lost much flesh; night sweats have persisted since Christmas ; complains of cough and dragging sensations in the right shoulder; bowels costive; tongue furred; appetite fair; skin rather anæmic; pulse 136 :

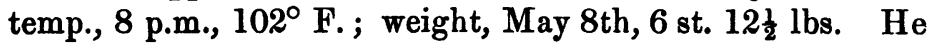
was carefully examined on May 5th, and no physical signs could be detected. The temperature was taken five times daily, and showed the usual pyrexia of first-stage phthisis, i.e. lower or normal records at 8 a.m., slightly raised at 11 a.m., and high after 2 p.m.

On May 8th dulness was detected over the left clavicle and crepitation below it.

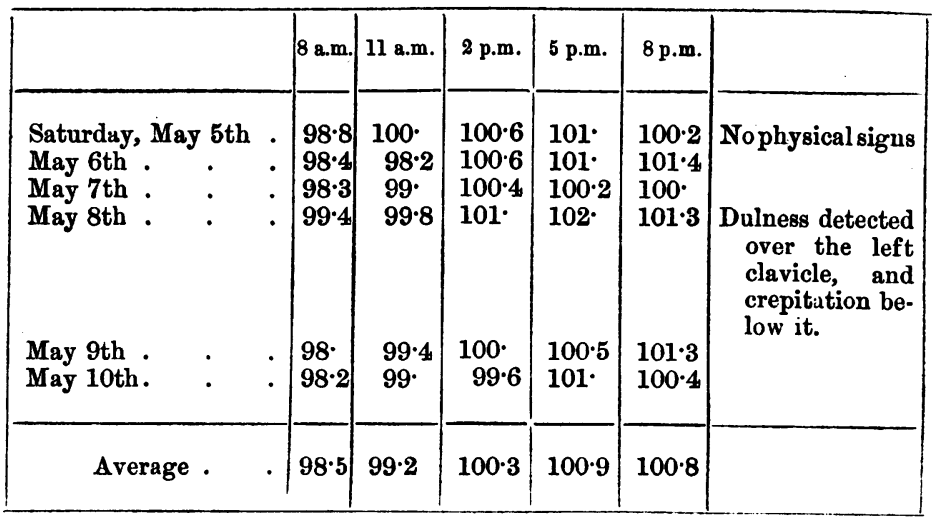


June 26th.-Dulness of the whole left side ; crepitation to third rib; crepitation above right scapula.

July 17th.-Crepitation to fourth rib on left side; coarse under clavicle; weight, 7 st. $1 \mathrm{lb}$., having never fallen since admission.

This case was a well-marked instance of the development of tubercle, and, as the rise in temperature preceded the appearance of physical signs, was confirmatory of Dr. Ringer's observation that we can often diagnose tubercle by the temperature before we can do so by physical signs.

The effect of extension of disease in the same lung is exemplified by Case 2, where the crepitation which had been confined to the apex of the lung extended to the whole of the lung (while the temperatures were being taken), and at a later date to both lungs. It will be observed that though there is a rise in the afternoon, yet with all the active disease going on the temperature does not rise high, and only twice reaches $100^{\circ} \mathrm{F}$.

CASE 2.--Richard D-, æt. 25, admitted into the Brompton Hospital, December 23rd, 1872.

History.-Mother and brother died of consumption; cough with expectoration two and a half years, succeeded six months later by an attack of slight pleurisy, followed by night sweats and wasting. Night sweats disappeared, but have returned within the last six months and are now profuse. Has wasted more or less for six months. Hæmoptysis to the amount of $3 \mathrm{j}$ eighteen months ago, and the expectoration has been streaked on several occasions.

At present.-Cough troublesome; tongue clean; appetite fair ; bowels regular ; pulse 80 ; resp. 24.

At the end of the first week of January the physical signs were "crepitation to fourth rib on the right side." The subjoined temperatures were then taken. 


\begin{tabular}{|c|c|c|c|c|c|c|c|c|}
\hline \multicolumn{4}{|c|}{ January, 1873.} & 8 a.m. & 11 a.m. & 2 p.m. & 5 p.m. & 8 p.m. \\
\hline 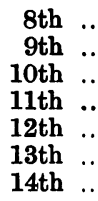 & $\begin{array}{l}\ldots \\
\ldots \\
\cdots \\
\ldots \\
\cdots \\
\ldots \\
\ldots\end{array}$ & $\begin{array}{l}\ldots \\
\cdots \\
\ldots \\
\cdots \\
\cdots \\
\ldots \\
\ldots\end{array}$ & $\begin{array}{l}\cdots \\
\cdots \\
\cdots \\
\cdots \\
\cdots \\
\cdots \\
\cdots\end{array}$ & $\begin{array}{l}98 \cdot \\
97^{\circ} \\
97 \cdot 2 \\
97 \cdot 1 \\
97 \cdot \\
96 \cdot 8 \\
96 \cdot 8\end{array}$ & $\begin{array}{l}98 \cdot 2 \\
98 \cdot \\
98 \cdot 8 \\
98 \cdot 6 \\
97 \cdot 8 \\
98 \cdot 1 \\
98 \cdot 2\end{array}$ & $\begin{array}{l}99 \cdot 2 \\
98 \cdot 8 \\
99 \cdot 5 \\
99 \cdot 4 \\
98 \cdot 6 \\
99 \cdot 1 \\
99 \cdot\end{array}$ & $\begin{array}{l}99 \cdot 3 \\
98 \cdot 4 \\
99 \cdot 4 \\
99 \cdot 6 \\
99 \cdot 2 \\
99 \cdot 4 \\
99 \cdot 4\end{array}$ & $\begin{array}{r}100 \cdot 2 \\
99 \cdot 6 \\
99 \cdot 3 \\
99 \cdot 4 \\
99 \cdot 4 \\
99 \cdot 6 \\
100 \cdot 2\end{array}$ \\
\hline Averag & $\ldots$ & $\ldots$ & & $97^{\circ} \mathrm{I}$ & $98 \cdot 2$ & $99 \cdot 1$ & $99^{\circ} 2$ & $99^{\circ} 5$ \\
\hline
\end{tabular}

January 30th, 1873.-Crepitation extends over the whole right front, and over the right interscapular region.

March 6th.-Crepitation has diminished in the upper portion of the right lung, but is now audible, scattered throughout both lungs front and back.

The above cases demonstrate the effect of tubercle formation in causing a definite rise in the temperature, which may cease when this process is complete. It is, however, by no means necessary that any rise should take place, and in several of my cases, where active disease has been going on in one or both lungs, no rise has taken place, but rather a low range of temperature has prevailed. Of this the subjoined is an instance.

CASE 3.-Janet S-, æt. 46, admitted into the Brompton Hospital, December 2nd, 1873.

History. - Subject for the last four years to cough in winter, which for the last two years has been continuous, and accompanied by loss of flesh. Night sweats for one year; slight hæmoptysis four years ago, and again, two years ago she brought up a pint of blood.

At present.-Cough troublesome, sputum yellow and frothy; night sweats profuse; pains under both clavicles, most under right; tongue clean; appetite good; bowels regular.

On the first of January the physical signs were- 
Right.-Dulness; crepitation upper third, front, and back. Left.-Crepitation audible over whole front and over interscapular region.

The following temperatures were taken two days later:

\begin{tabular}{|c|c|c|c|c|c|c|}
\hline January. & & 8 a.m. & 11 a.m. & 2 p.m. & 5 p.m. & $8 \mathrm{p} . \mathrm{m}$. \\
\hline $\begin{array}{l}\text { 14th. } \\
\text { 15th. } \\
\text { 16th. } \\
\text { 17th. } \\
\text { 18th . } \\
\text { 19th . } \\
\text { 20th. }\end{array}$ & . & $\begin{array}{l}98 \cdot \\
97 \cdot \\
98 \cdot 2 \\
97 \cdot 6 \\
97 \cdot 9 \\
98 \cdot \\
97 \cdot 6\end{array}$ & $\begin{array}{l}98 \cdot 2 \\
98 \cdot \\
98 \cdot \\
98 \cdot \\
97 \cdot \\
98 \cdot 2 \\
98 \cdot\end{array}$ & $\begin{array}{l}98 \cdot 8 \\
98 \cdot 3 \\
97 \cdot 8 \\
98 \cdot 6 \\
98 \cdot 4 \\
97 \cdot 6 \\
98 \cdot 6\end{array}$ & $\begin{array}{l}98 \cdot 6 \\
98 \cdot \\
98 \cdot \\
98 \cdot 6 \\
98 \cdot \\
98 \cdot 4 \\
98 \cdot 4\end{array}$ & $\begin{array}{l}99^{\cdot} \\
98 \cdot 4 \\
98 \cdot 2 \\
99 \cdot \\
98 \cdot 8 \\
98 \cdot 4 \\
98 \cdot 2\end{array}$ \\
\hline Average & & $97^{\circ} 7$ & $97^{\circ} 9$ & $98^{\circ}$ & $98 \cdot 3$ & $98 \cdot 6$ \\
\hline
\end{tabular}

January 5th.-Hæmoptysis to the amount of $z^{\text {iss; no }}$ increase of cough followed.

19th.-Profuse night sweats.

30th.-Physical signs the same.

Upwards of 200 observations on the class of first stage active were made in twenty-six patients, at the hours 8,10 , 11 a.m. 2, 5, 8, and 11 p.m., and the results are embodied in Table I, which records, under the various temperatures, the number of times each was noted, as well as the relative percentages. The last five columns express the maximum, mean, and minimum temperatures, taken at each hour, as well as the number of cases, and number of observations made on them.

Attention is especially drawn to the fifth and twelfth columns, as these contain the totals of observations of the pyrexial $\left(100^{\circ}\right.$ and over) and of subnormal (under $98^{\circ}$ ) types, with their respective percentages, and a glance at these will give the reader of this and the succeeding tables at once the gist of the contents. 


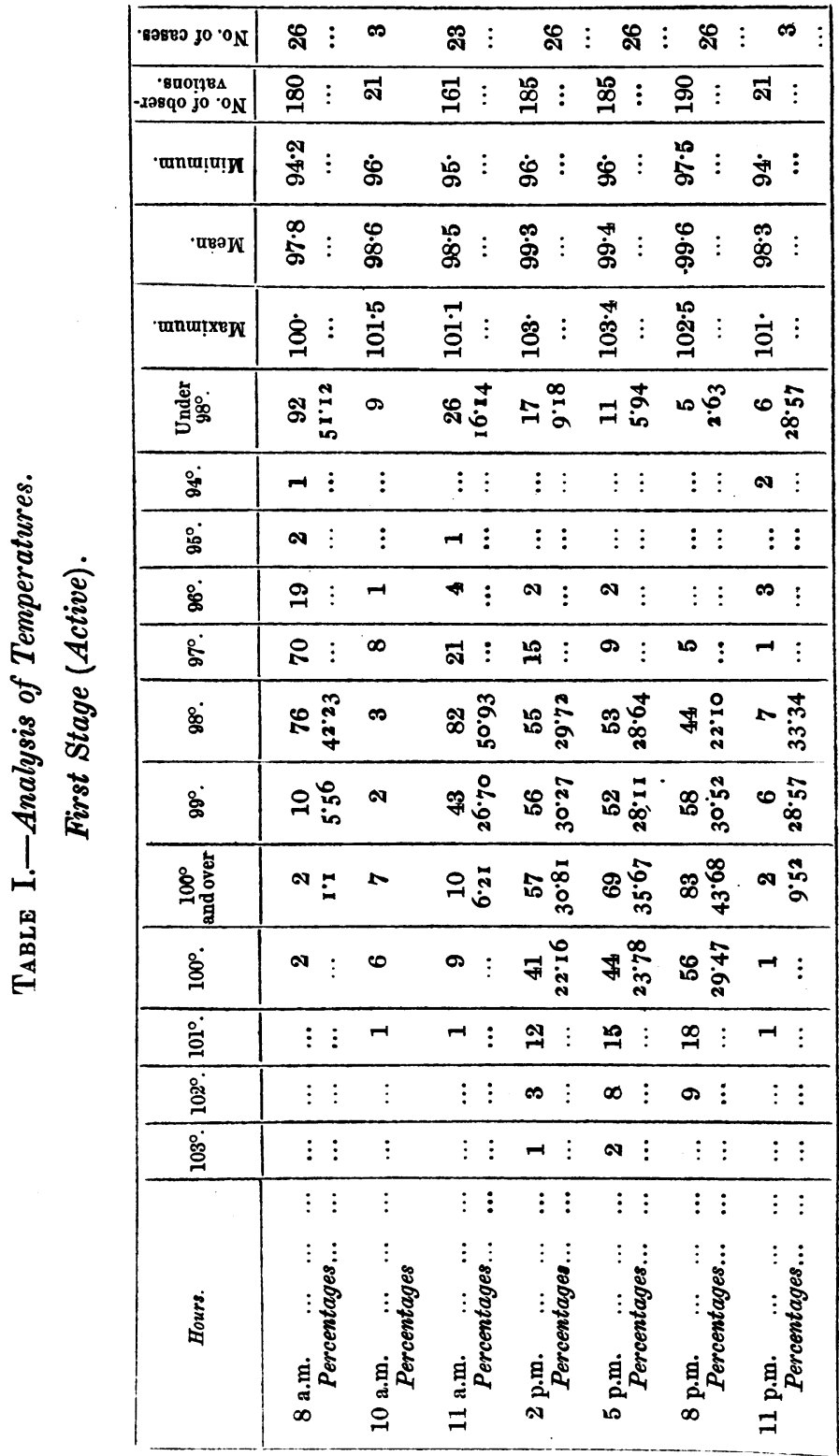


By this method I hope to put the Fellows of the Society in full possession, not only of the results, but also of the facts on which these results are based. The observations taken at 8 a.m. exhibit remarkably low temperatures; 51 per cent. are below $98^{\circ}, 42$ per cent. between $98^{\circ}$ and $99^{\circ}$, while only $5 \frac{1}{2}$ per cent. rise to between $99^{\circ}$ and $100^{\circ}$, and 1 per cent. reaches $100^{\circ}$; and as this last temperature $\left(100^{\circ}\right)$ was only recorded in one case on two occasions, it may fairly be considered as accidental.

The mean temperature is $97 \cdot 8^{\circ}$, while the minimum falls as low as $94 \cdot 2^{\circ}$.

The notes at 10 a.m. show a slight rise from the subnormal state, which is more marked at 11 o'clock, when we find only 16 per cent. below $98^{\circ}, 50$ per cent. between $98^{\circ}$ and $99^{\circ}$, and 6 per cent. above $100^{\circ}$; the mean temperature being $98.5^{\circ}$, the minimum $95^{\circ}$. The 2 p.m. and 5 p.m. observations show a steady continuance of this rise, the subnormal temperatures diminishing and the pyrexial increasing, until at $8 \mathrm{p} . \mathrm{m}$. the climax is reached, only $2 \frac{1}{\mathrm{a}}$ per cent. being subnormal, and more than 43 per cent. exceeding $100^{\circ}$; the maximum being $102.5^{\circ}$, the mean $99 \cdot 6^{\circ}$, and the minimum $97 \cdot 5^{\circ}$.

The 11 p.m. notes show a rapid fall, $28 \frac{1}{2}$ per cent. being subnormal, 33 per cent. normal, and only $9 \frac{1}{2}$ per cent. above $100^{\circ}$. The dotted line (see Plate III, fig. 1, No. 1) expresses roughly the day-temperature course of Class $I$ as far as can be ascertained from observations taken seven times per diem in these twenty-six cases; but in order to display the night phenomena and to give a fuller insight into the day variations a second continuous line (see Plate III, fig. 1, No. 2) has been annexed which shows twenty-four hourly observations on one of the same patients, and this may be compared with the dotted one.

Though this case was hardly a typical one, the general course may be said to confirm the dotted line, especially in respect of the rise, which, it would appear, dates from the morning hours. It shows a slight exacerbation at 10 a.m. and a consequent fall, and then a nearly continuous though

vol. LviIt. 
slight rise from 2 p.m. till 10 o'clock, when a rapid fall commences, which reaches its lowest ebb between 2 and 3 a.m. Temperatures of $94^{\circ}$ and $95^{\circ}$ are then not unfrequently recorded.

The next class, Class II, is that of the first stage, quiescent (Plate III, fig. 2).

This is the ordinary "chronic first stage" of authors, of which an instance is subjoined, though its common occurrence in practice renders it familiar to every one.

CASE 4.-Julia E-, æt. 21, admitted into Hall Ward under Dr. Quain, April 14th, 1874. Maternal aunt died of phthisis. Cough with expectoration and wasting six months; worse for four months ; hæmoptysis, $3 \mathrm{j}$, four months ago, and to slighter amount once since. Night sweats occurred at the same period, but have since ceased. Appetite bad; tongue furred; catamenia scanty and irregular for nine months; bowels confined; pulse quiet.

Physical signs, May 13th, 1874.-Dulness and tubular sounds over upper third of right lung; no night sweats; expectoration slight.

The subjoined observations were then taken :

\begin{tabular}{|c|c|c|c|c|c|c|c|c|c|}
\hline \multicolumn{3}{|c|}{ Date. } & 8 a.m. & 11 a.m. & 2 p.m. & 5 p.m. & 8 p.m. & 11 p.m. & Pulse. \\
\hline $\begin{array}{cc}\text { May 14th } \\
\text { " 15th } \\
\text { " 16th } \\
\text { " 17th } \\
\text { " 18th } \\
\text { 19th } \\
\text { " 20th } \\
\text { 21st }\end{array}$ & $\begin{array}{l}\dot{.} \\
\dot{.} \\
\dot{.} \\
\dot{.}\end{array}$ & $\begin{array}{l}\cdot \\
:\end{array}$ & $\begin{array}{l}97 \cdot 6 \\
98 \cdot 4 \\
97 \cdot 4 \\
98 \cdot 4 \\
97 \cdot 4 \\
97 \cdot 2 \\
97 \cdot 4\end{array}$ & $\begin{array}{l}\mathbf{9 8 \cdot 2} \\
98 \cdot 2 \\
97 \cdot 6 \\
97 \cdot \\
97 \cdot 4 \\
97 \cdot 8 \\
97 \cdot 2 \\
97 \cdot\end{array}$ & $\begin{array}{l}\mathbf{9 8} \cdot 4 \\
\mathbf{9 8} \cdot 4 \\
\mathbf{9 7 \cdot 2} \\
\mathbf{9 6 \cdot 2} \\
\mathbf{9 7 \cdot 8} \\
\mathbf{9 8 \cdot 2} \\
\mathbf{9 7 \cdot} \\
\mathbf{9 9 \cdot 6}\end{array}$ & $\begin{array}{c}\dddot{97} \cdot \\
97 \cdot 2 \\
97 \cdot 6 \\
98 \cdot 2 \\
97 \cdot \\
98 \cdot 6 \\
101 \cdot 2\end{array}$ & $\begin{array}{l}98 \cdot \\
97 \cdot 4 \\
98 \cdot 6 \\
97 \cdot 4 \\
97 \cdot 6 \\
97 \cdot 4 \\
97 \cdot \\
99 \cdot 4\end{array}$ & $\begin{array}{c}\ldots \\
\ldots \\
\ldots 7 \cdot 2 \\
\ldots \\
\ldots \\
\ldots \\
\ldots\end{array}$ & $\begin{array}{l}64 \\
64 \\
64 \\
60 \\
72 \\
60 \\
56 \\
68\end{array}$ \\
\hline Average & ${ }^{\circ}$ & - $\quad$. & $97^{\circ} 7$ & $97^{\circ} 5$ & $97 \cdot 8$ & $99^{\circ} 5$ & $97 \cdot 8$ & $\cdots$ & $\cdots$ \\
\hline
\end{tabular}

May 22nd.-Physical signs the same.

No marked change is indicated by the 8 o'clock records, when the mean is $98.4^{\circ}$; after this period a distinct fall 
takes place, which, as in the acute first stage, continues till the early morning hours. I have made a series of hourly observations in one case for twenty-four hours to gain some insight into the night temperatures, and the result is seen in the continuous line.

The patient was a male, æt. 36, with well-marked physical signs of consolidation over the upper third of the left lung, and no advance in the signs had been detected during the two months he had been under observation. The temperatures are chiefly normal in character, with the slight tendency to afternoon rise which seems to be often present. The continuous line in this diagram (Plate III, fig. 2, No. 2) gives the cycle in this instance.

Table II is based on between thirty and forty obser. vations made on five patients of this class at each of the following hours, viz. -8 and 11 a.m.; 2, 5, and 8 p.m.; a few were made at 11 p.m. which confirm the general course (see page 84 ).

The 8 a.m. observations indicate subnormal temperatures, the mean being $97 \cdot 3^{\circ}$, the minimum $95.2^{\circ}$, and the maximum $98.5^{\circ}$; 63 per cent. fell below $98^{\circ}$, and the re. mainder are all below $99^{\circ}$. At 11 o'clock the temperatures are still low, the average being $97 \cdot 9^{\circ}$, the minimum $95 \cdot 2^{\circ}$. There is a slight increase, however, in the percentages under the heads of $98^{\circ}$ and $99^{\circ}$.

The further notes show a steady rise at 2 p.m., which reaches its maximum at 5 , an average of $98 \cdot 7^{\circ}$ being then attained, for though at 2 p.m. $8 \frac{1}{3}$ per cent. exceeded $100^{\circ}$, the average was only $98 \cdot 6^{\circ}$.

The next class is second stage (Plate III, fig. 2, No. 3), and under it are included only cases where no cavity has hitherto existed, but where the course of the physical signs clearly demonstrates one to be in process of formation. The signs principally relied on have been the increasing coarseness of the crepitation, the hoarse and croaking rhonchus, confined to a portion of one lung and combined with tubular sounds, and often high-pitched percussion note. In most cases the large increase of expectoration and the detection of elastic tissue 


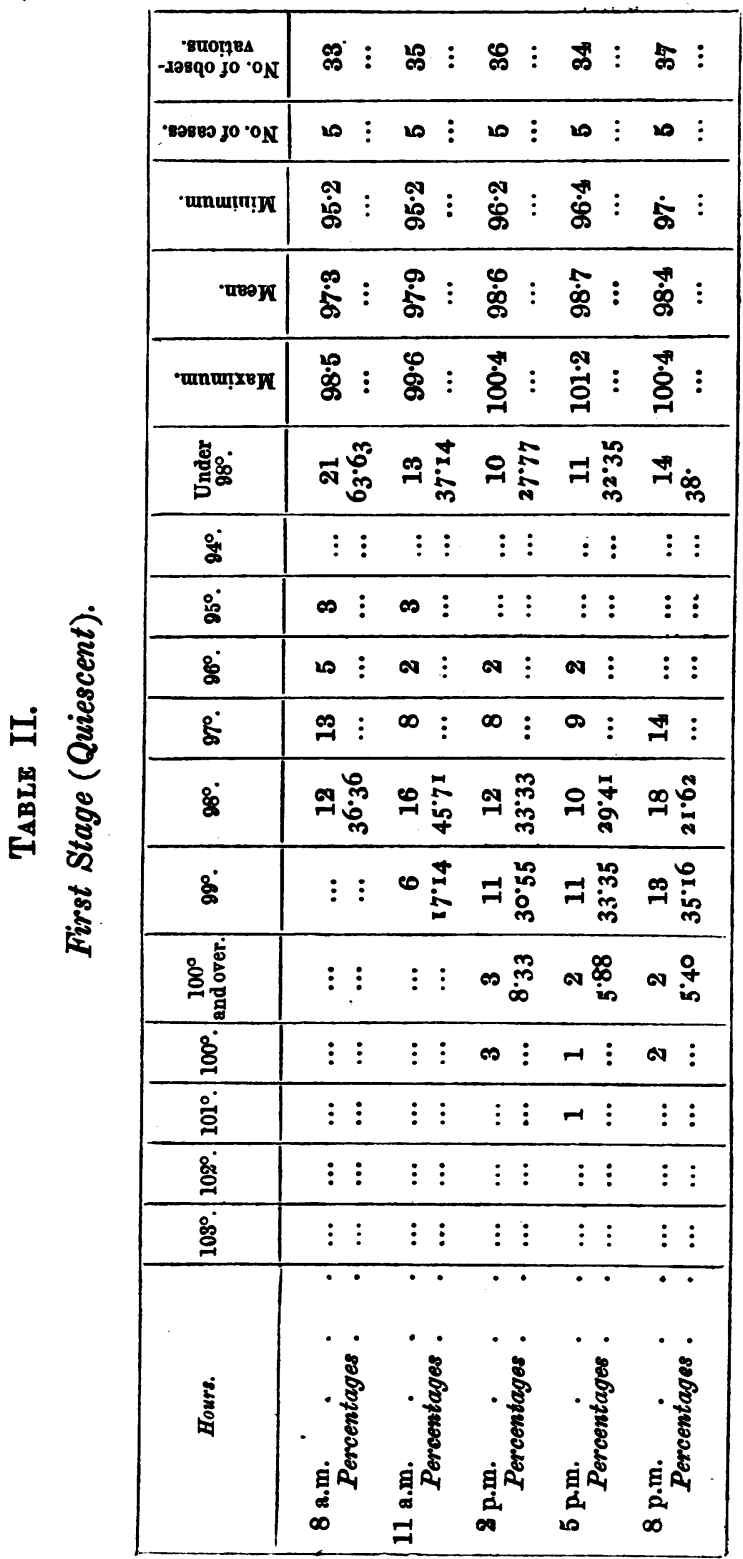


in it have confirmed the physical signs. In many of the cavity cases, which we shall presently consider, softening was proceeding in the opposite lung, or in another part of the same lung, but here, as a suppurating surface already existed in the form of a cavity, which might considerably influence the temperature, it was deemed advisable to separate these cases from other cases of softening and to class them under the heading "Active third stage."

We will now consider the process of softening in its thermal relations.

The observations were made on ten patients, at the same hours as in the preceding class, between seventy and eighty records being taken at each period, and of these, two examples, where the physical signs can be compared with the temperatures, are annexed. In the first one (Case 5) the formation of a cavity was proved by physical signs and the presence of yellow elastic tissue in the expectoration, the excavation being accompanied by a rise of temperature. In the second (Case 6) excavation was proved by physical signs alone, and gave rise to no pyrexia.

CASE 5.-Elizabeth B-, æt. 28, single, admitted into the Hospital for Consumption, January 21st, 1873. Mother died of phthisis. Subject to winter cough for six years, worse last winter, and continuous since. Dyspnœa for seven months. Slight hæmoptysis and night sweats last May, and has been losing flesh ever since. Catamenia ceased in May, but have reappeared in October, and are now regular. Cough troublesome, with expectoration; pulse 80. Crepitation is audible over the upper third of the left front chest.

February 17th, 1873.-Cough worse, with muco-purulent expectoration; respirations 32 ; croaking crepitation audible in the first interspace on the left side; coarse crepitation from the second to the fourth rib; croaking crepitation in the upper half of the left back. The subjoined temperatures were then taken. 


\begin{tabular}{|c|c|c|c|c|c|c|c|}
\hline \multicolumn{3}{|c|}{ Date. } & 8 a.m. & 11 a.m. & 2 p.m. & 5 p.m. & 8 p.m. \\
\hline $\begin{array}{c}\text { February } \\
" \\
" \\
" \\
" \\
"\end{array}$ & $\begin{array}{l}\text { 18th } \\
\text { 19th } \\
\text { 20th } \\
\text { 21st } \\
\text { 22nd } \\
\text { 23rd } \\
\text { 24th }\end{array}$ & : & $\begin{array}{l}98 \cdot \\
98 \cdot 6 \\
99 \cdot 6 \\
98 \cdot 2 \\
97 \cdot 8 \\
98 \cdot \\
98 .\end{array}$ & $\begin{array}{c}99 \cdot \\
99 \cdot \\
99 \cdot 6 \\
99 \cdot \\
100 \cdot 4 \\
99 \cdot 2 \\
98^{\circ}\end{array}$ & $\begin{array}{c}99^{\cdot 2} \\
99^{\circ} \\
99^{\circ} \\
98^{\circ} 6 \\
99^{\circ} \\
99^{\circ} \\
100^{\circ} 6\end{array}$ & $\begin{array}{r}100 . \\
100 \cdot \\
100 \cdot 2 \\
99 \cdot 8 \\
98 \cdot 6 \\
100 \cdot 2 \\
98 \cdot 8\end{array}$ & $\begin{array}{c}101 \cdot 4 \\
101 \cdot \\
100 . \\
100 \cdot 8 \\
98 \cdot 8 \\
100 \cdot 2 \\
99 .\end{array}$ \\
\hline Mean & - & & 98.3 & $99 \cdot 2$ & $99 \cdot 3$ & $99 \cdot 7$ & $100: 2$ \\
\hline
\end{tabular}

20th.-Yellow elastic tissue detected in the sputum, which is abundant, amounting to half a pint daily.

March 5th,-Well-marked cavernous gurgle in upper left ohest.

April 15th.-Dry cavernous sound to the second rib; some croaking respiration above the scapula; cough easier; expectoration small in amount. Has lost $6 \frac{1}{2} \mathrm{lbs}$. during her stay in the hospital.

CaSs 6.-Edwin N-, æt. 23, carpenter, admitted into the Hospital for Consumption, January 29, 1873.

History.-Continuous cough for one year. Slight hæmoptysis last May, accompanied by pain in the left chest, and has been wasting ever since. Night sweats on and off since May, with dyspnœa on exertion. Tongue clean; appetite bad; bowels regular; pulse 100; respirations 24; cough troublesome.

On admission the physical signs were dulness and crepitation in the first interspace on the left side.

On March 13th the disease had extended, and crepitation was audible over the upper half of the left chest posteriorly. Crepitation was discoverable over the whole left front, and was of a croaking character in the npper half.

The temperature was then taken five times a day, and the subjoined is the chart. 


\begin{tabular}{|c|c|c|c|c|c|c|c|}
\hline \multicolumn{3}{|c|}{ Date. } & 8 a.m. & 11 a.m. & 2 p.m. & 5 p.m. & 8 p.m. \\
\hline $\begin{array}{cc}\text { March } & \text { 20th } \\
\text { " } & \text { 21st } \\
\text { " } & \text { 22nd } \\
\text { " } & \text { 23rd } \\
" & \text { 24th } \\
" & 25 \text { th } \\
" & 26 \text { th } \\
\text { " } & \text { 27th }\end{array}$ & $\begin{array}{l}\dot{ } \\
\dot{ } \\
\dot{ } \\
\dot{ }\end{array}$ & • & $\begin{array}{l}98 \cdot 8 \\
98^{\circ} \\
98^{\circ} \\
95 \cdot 6 \\
96^{\circ} \\
97^{\circ} \\
98^{\circ} \\
97^{\circ} 4\end{array}$ & $\begin{array}{l}99 \cdot 4 \\
99^{\circ} \\
99^{\cdot} \\
98 \cdot \\
98 \cdot 6 \\
99^{\circ} \\
98 \cdot 2 \\
98 \cdot\end{array}$ & $\begin{array}{l}99 \cdot 6 \\
97^{\circ} \\
98 \cdot 8 \\
98^{\circ} \\
99^{\circ} \\
98 \cdot 2 \\
98 \cdot 4 \\
98 \cdot 6\end{array}$ & $\begin{array}{l}98 \cdot 4 \\
99 \cdot \\
98 \cdot 6 \\
98 \cdot 2 \\
99 \cdot 4 \\
99 \cdot \\
98 \cdot 2 \\
\ldots .\end{array}$ & $\begin{array}{c}97 \cdot 6 \\
98^{\circ} \\
98 \cdot 2 \\
98^{\circ} \\
100^{\circ} \\
99^{\circ} \\
99 \cdot 2 \\
\ldots . .\end{array}$ \\
\hline Mean & & & $97 \cdot 4$ & $98 \cdot 6$ & $98 \cdot 4$ & $98 \cdot 7$ & 98.5 \\
\hline
\end{tabular}

March 27th.-Cavernous gurgle detected in upper left front. Patches of urticaria have appeared on the patient's body.

Let us now consider the statistics of the second stage as set forth in Table III (see page 88).

At 8 a.m. the temperatures are somewhat higher than in the first stage, $37 \frac{1}{2}$ per cent. being below $98^{\circ}, 42 \frac{1}{2}$ per cent. between $98^{\circ}$ and $99^{\circ}$, and 5 per cent. exceeding $100^{\circ}$; the mean being $98 \cdot 1^{\circ}$, and the minimum $95 \cdot 6^{\circ}$.

At 11 o'clock a rise has taken place, the temperatures exceeding $100^{\circ}$ being $27 \frac{1}{2}$ per cent., and those below $98^{\circ}$ $10 \frac{1}{2}$ per cent.; the mean $99 \cdot 1^{\circ}$, the minimum $96 \cdot 8^{\circ}$.

A steady rise appears to take place till 8 p.m., the percentages above 100 , at 2,5 , and 8 p.m., being respectively $40,42 \frac{3}{4}$, and 52 , and the means $99 \cdot 6^{\circ}, 99 \cdot 5^{\circ}$, and $99 \cdot 7^{\circ}$; the highest temperature recorded, $103 \cdot 6^{\circ}$, being noted at 8 o'clock.

The chart of this class has been depicted with open crossed dots (see Plate III, fig. 2, No. 3), and seems to indicate a continuous ascent during the day. Unfortunately I have not been able hitherto to observe many of the night temperatures, and therefore this cycle is at present incomplete.

The day observations, however, resemble those of the first stage in the low morning temperatures, but differ from them in exhibiting a more continuous rise from 8 a.m. to 8 p.m, 


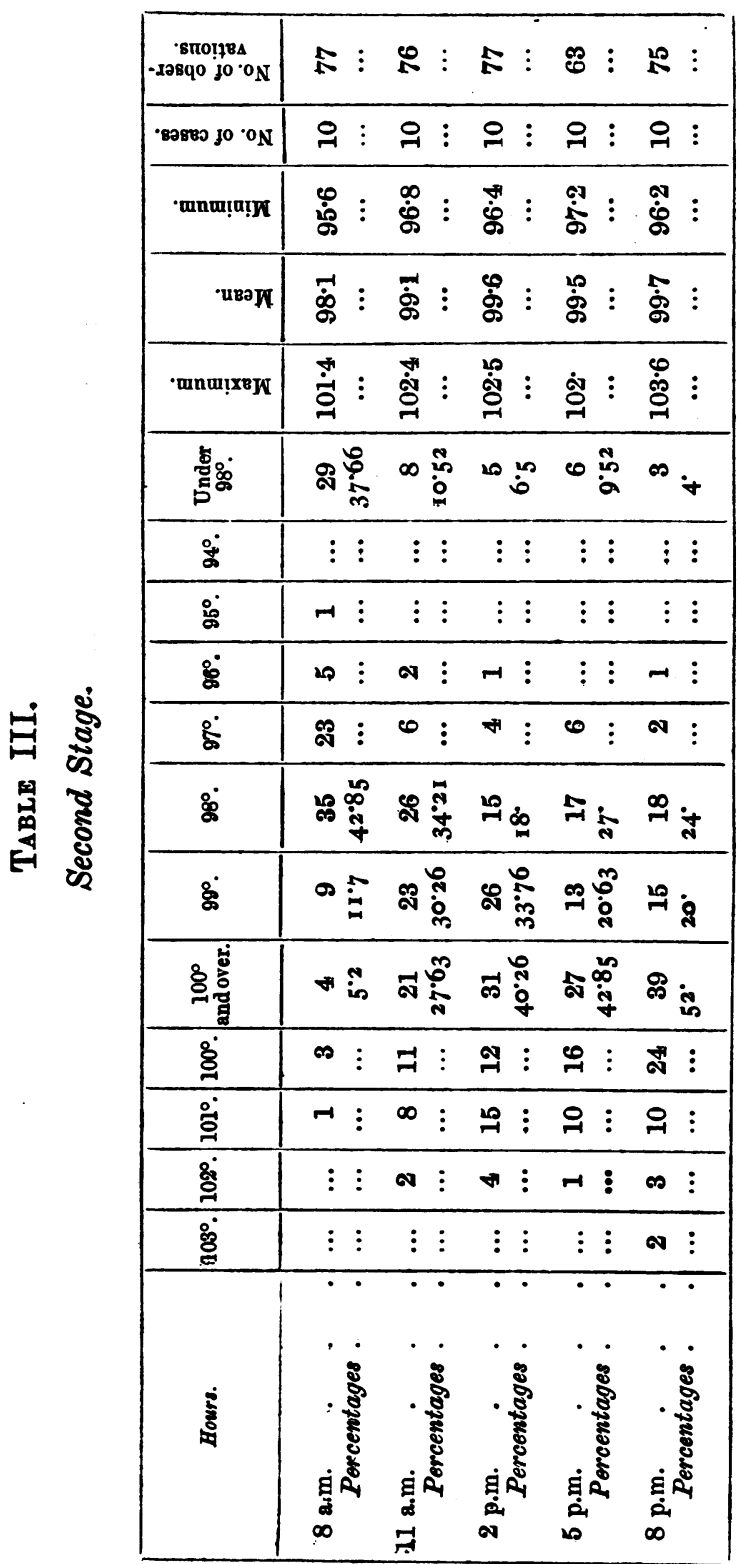


The third stage active class (Plate IV, fig. 1) has been subjected to more thermometrical observations than any other, because the clinical and pathological phenomena which distinguish it are more distinctly phthisical than those of other stages. The crepitation accompanying tubercle formation may be mistaken for that of acute or chronic pneumonia, though the variations in the râles and their more scattered nature ought to give the key to a diagnosis. The rhonchus and sibilus which often usher in tuberculosis may be confused with asthma or bronchitis, until the serious character of the phenomena forces itself into notice, but the physical signs and clinical symptoms of an active third stage case are unmistakable. The large amount of purulent expectoration, the hectic aspect, the wasting, the night sweats, combined with the existence of cavernous sounds in the upper portions of the lungs, are referable to nothing else than a phthisical cavity discharging matter from its surface, or extending itself by further excavation, this being rendered indisputable by the presence of lung-tissue in the sputum.

The position of the signs, the character of the expectoration, and other clinical phenomena, at once separate cases of bronchial dilatation from this category.

While, holvever, it is easy to decide on the existence of a cavity, and to assign many of the symptoms to suppuration going on in the lung, a difficulty arises when in addition to this there is evidence of fresh tubercle forming either in the same or in the opposite lung. The question then arises, to which are we to assign the thermometrical phenomenato the abscess symptoms, if I may so call them, or to the tubercle symptoms?

It is hard to say, though probably the purulent processes exercise the greater influence, but a comparison between the first stage active and third stage active may throw some light on the subject.

I wish, however, to be clearly understood that in some of these forty-three cases the discharging cavity was accom. panied by an increasing amount of tuberculization.

I subjoin an illustrative case of this class, in which 
observations were taken seven times a day for twenty-two days, and shortly before the patient's death for two series of twenty-four consecutive hours.

Case 7.-Maurice A-, æet. 22, married, was admitted into the South branch of the hospital, April 7th, 1874.

History.-Had lost some maternal aunts from phthisis. Had suffered from general weakness for eight months, for four had had cough with expectoration, slight loss of flesh, and night sweats. Complains of pain in the back ; indigestion after meals. Is very anæmic. Cough very troublesome at night, expectoration muco-purulent. Tongue furred; appetite moderate.

Physical signs.-Cavernous sounds audible to the fourth rib, right front. Weight (April 13th) 9 st. 7 lbs.

April 30th.-Has gradually become worse. Temperature and pulse have risen, and appetite has fallen off. Weight 9 st. 4 lbs. (a loss of 3 lbs.). In addition to above signs crepitation is audible under left clavicle, and tubular sounds in second intercostal space. Transferred to the main hospital in order to be more carefully attended to, as he is now confined to bed.

The following observations were then taken :

\begin{tabular}{|c|c|c|c|c|c|c|c|c|}
\hline May. & 8 a.m. & 11 a.m. & 2 p.m. & 5 p.m. & 8 p.m. & Resp. & Pulse. & Physical signs. \\
\hline 8th. & $98 \cdot 4$ & $100^{\circ}$ & 100 & $100^{\circ}$ & $100^{\circ}$ & 30 & 104 & May 7th.-Right: \\
\hline 9th. & $99 \cdot 9$ & $99 \cdot 8$ & $98 \cdot 8$ & $98 \cdot 5$ & $100 \cdot 2$ & $\cdots$ & $\ldots$ & to 4th rib, and \\
\hline 10th. & $98 \cdot 9$ & $99 \cdot 8$ & $100 \cdot 2$ & $100 \cdot 2$ & $99 \cdot 2$ & $\cdots$ & ... & Crepitation in \\
\hline 11th. & $99 \cdot 4$ & $99 \cdot 8$ & $100 \cdot 2$ & $100 \cdot 6$ & $100 \cdot 6$ & 32 & 100 & nest. \\
\hline 12th. & $99 \cdot 9$ & $99 \cdot 4$ & $100 \cdot 6$ & $98 \cdot 9$ & $100 \cdot 6$ & 34 & 104 & \\
\hline 13th. & $97 \cdot 8$ & $100 \cdot 2$ & $99 \cdot 9$ & $99 \cdot 4$ & $100 \cdot 4$ & 36 & 112 & \\
\hline 14th. & $100 \cdot 2$ & 102 & $100 \cdot 2$ & 100 & $101 \cdot 2$ & $\ldots$ & ... & \\
\hline
\end{tabular}

The hours for taking the temperature were then changed to $11,2,5,8,10$ and 12 . 
PHTHISIS PULMONALIS.

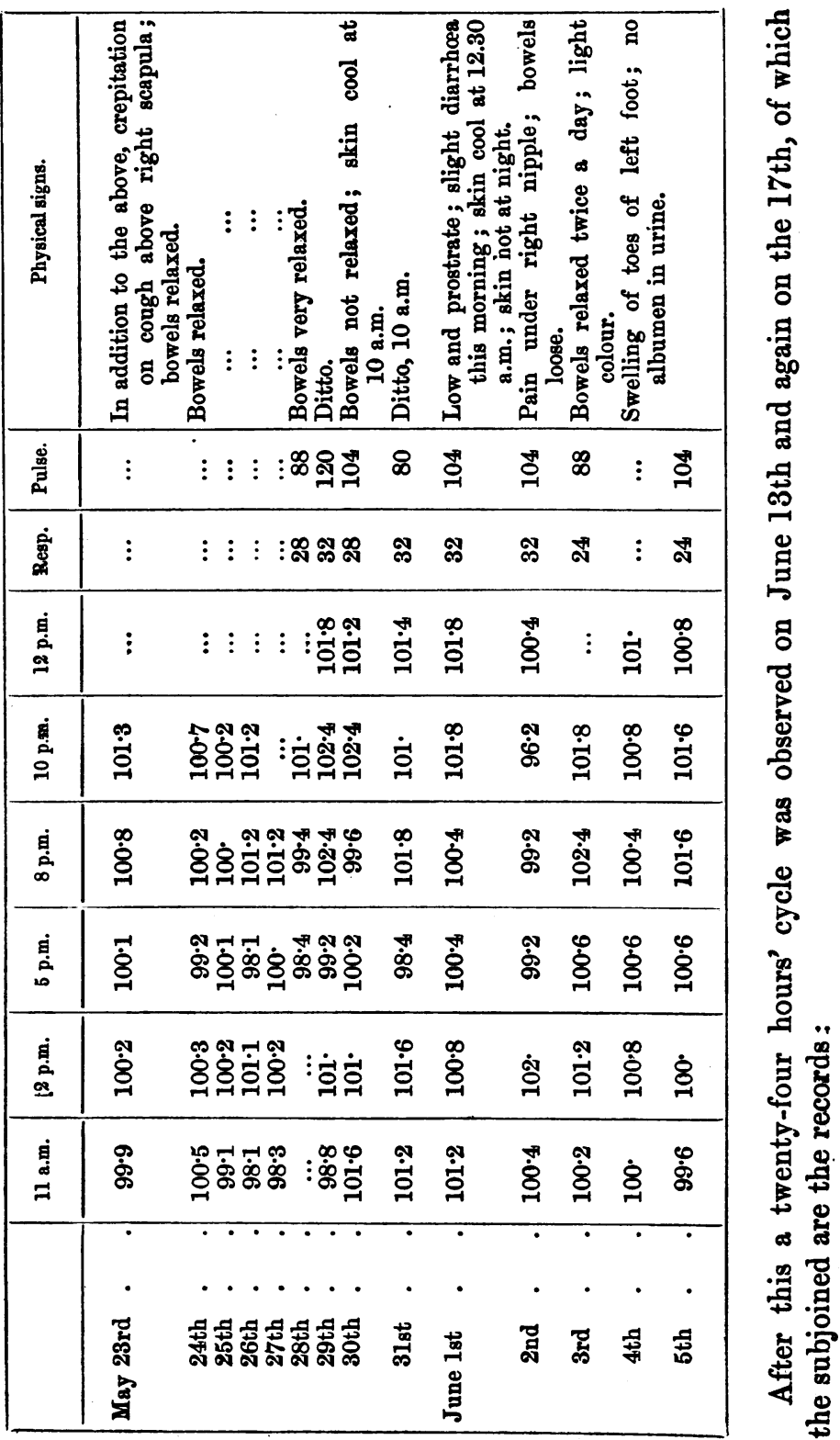




\begin{tabular}{|c|c|c|c|c|c|}
\hline $\begin{array}{l}\text { 总 } \\
\text { 恶 } \\
\text { 意 }\end{array}$ & \multicolumn{5}{|c|}{ 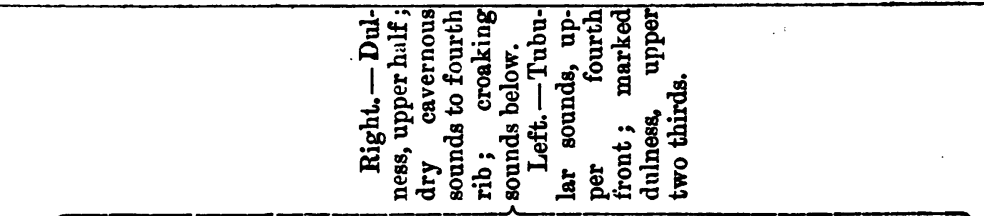 } \\
\hline 离 & 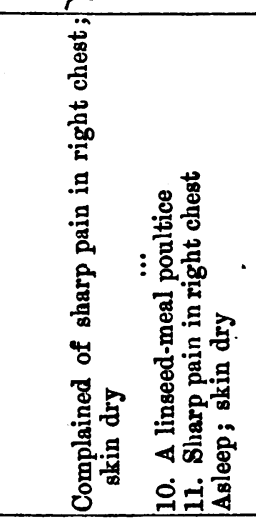 & 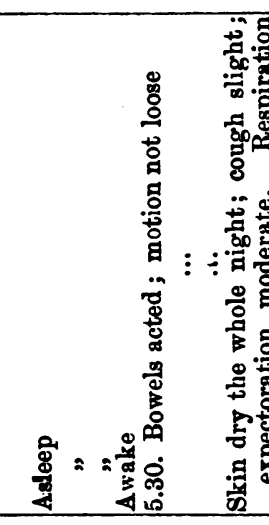 & 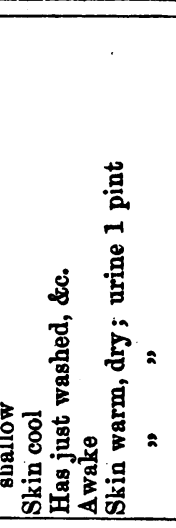 & 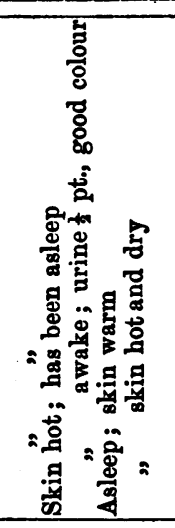 & 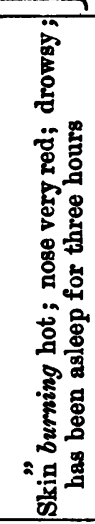 \\
\hline 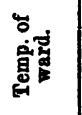 & क⿺⿻一⿰冫⿰亅⿱丿丶丶 $2=2$ & $=2=$ : & $\vdots: \vdots:$ : & : & $\vdots \vdots$ \\
\hline छ্ّة & 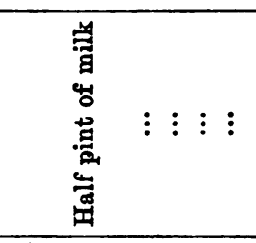 & 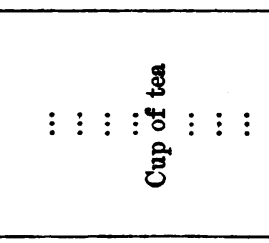 & 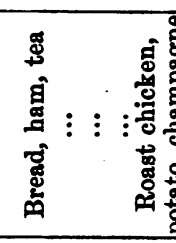 & 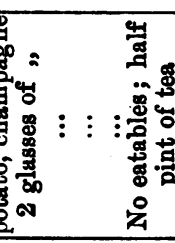 & \\
\hline 高 & 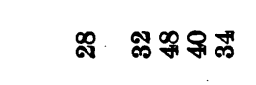 & 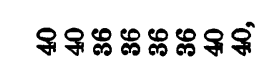 & 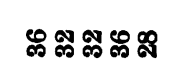 & 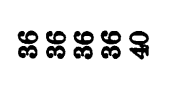 & 京邑 \\
\hline 离 & 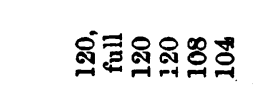 & 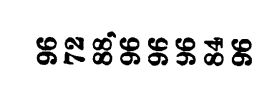 & 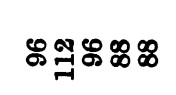 & 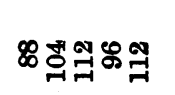 & 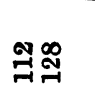 \\
\hline 疍安 & 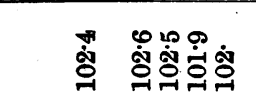 & 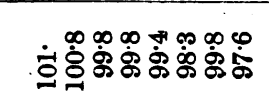 & ஜ்ீ人் & 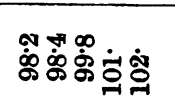 & 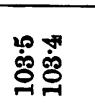 \\
\hline 䙷 & 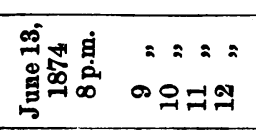 & 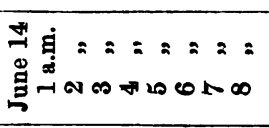 & 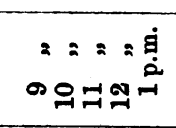 & $\begin{array}{l}=:=2: \\
N=0000\end{array}$ & $\therefore=$ \\
\hline
\end{tabular}




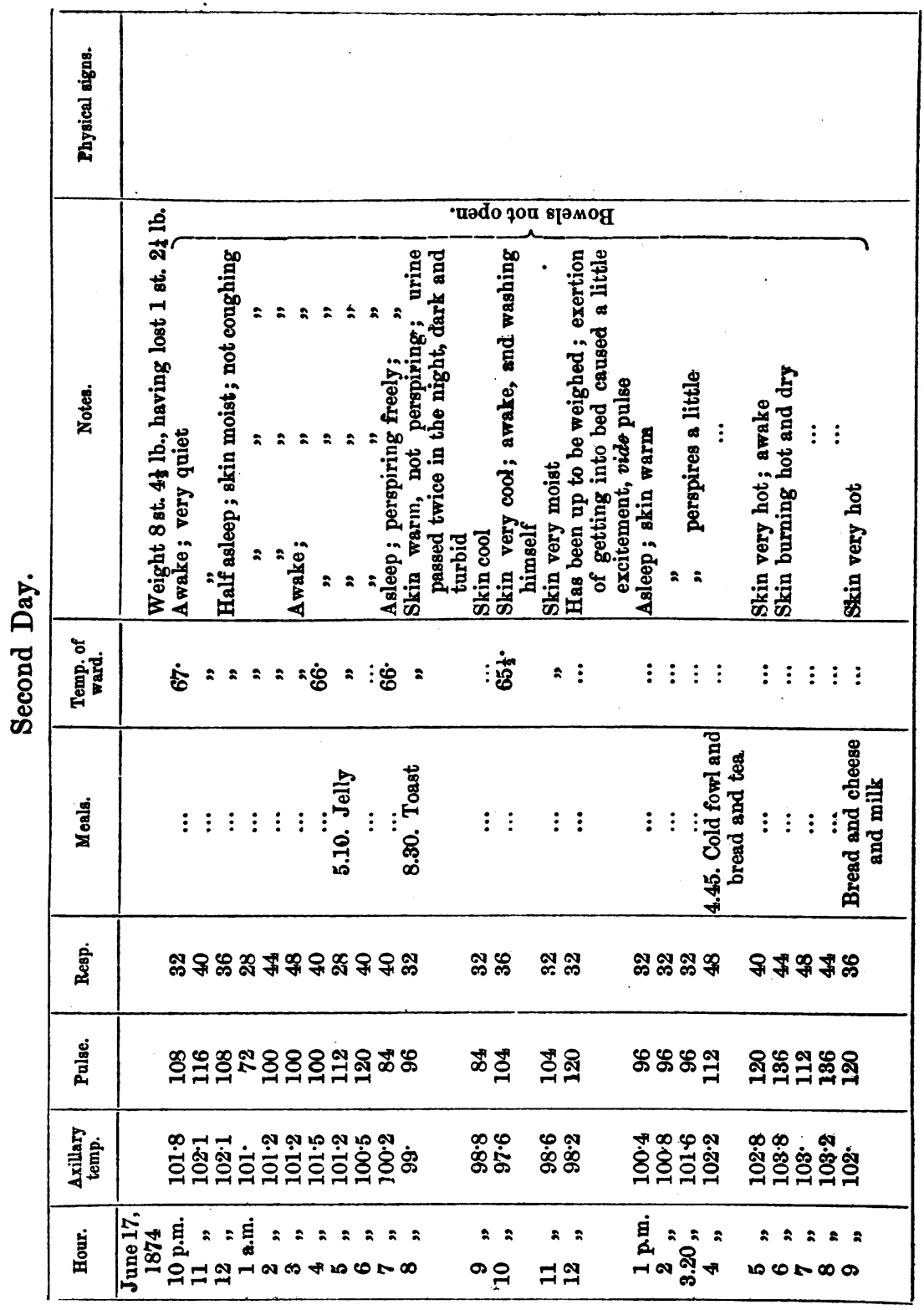


June 22nd.-Seized with pain under right nipple on the morning of the 21st, which has continued ever since. Breath has been very difficult; patient has almost sunk from exhaustion ; aspect pale and anxious ; tongue red-furred in centre ; pulse 120 , resp. 48 , temp. $99^{\circ}$ (afternoon); crepitation, posterior right base; right side more resonant than left.

23rd.-Crepitation now audible over the whole right side, and cavernous sounds as above.

24th.-Feels relieved and ate a fair dinner (chicken); left leg swollen and cedematous; swelling in popliteal space tender on pressure, proceeding probably from plugging of veins.

Died on the 26th.

\begin{tabular}{|c|c|c|c|c|c|c|c|c|}
\hline Summary. : & At 8 a.m. & 11 a.m. & 2 p.m. & 5 p.m. & 8 p.m. & 10 p.m. & 12 p.m \\
\hline Averages . . & $99^{\circ}$ & $99^{\circ} 7$ & $100 \cdot 4$ & $100 \cdot 3$ & $100 \cdot 9$ & $101^{\cdot} 1$ & $101^{\circ} 4$ \\
\hline No. of observations . & 9 & 22 & 22 & 23 & 24 & 15 & 9 \\
\hline
\end{tabular}

Autopsy twenty-four hours after death.

Both lungs somewhat collapsed. Right lung weighed 2 lbs. 11 oz., and was firmly adherent; the upper lobe appeared to be completely excavated, consisting of a mere bag of pleura; the lower and middle were consolidated with aggregations of miliary tubercle, in which centres of softening were visible; the middle lobe contained a small cavity of recent formation.

Left lung 2 lbs. 5 oz. ; adherent ; upper third appears to be consolidated with aggregations of miliary tubercle, caseating in parts, and showing a few small cavities, one the size of a walnut; lower lobe consolidated with ordinary red pneumonic hepatization. Its upper border contained a few grey aggregations.

Liver of nutmeg appearance, weight 4 lbs. 7 oz.

Intestines.-Mucous membrane of small intestine much injected. Solitary glands of ileum were caseous; some had 
broken down and formed ulcers. The cæcum was one mass of ulceration.

The case only lasted six and a half months, and the postmortem results may be summed up as-Excavations and recent tuberculisation of both lungs, with tuberculosis and ulceration of the intestines. The temperature course was highly pyrexial, but exhibited those periods of collapse which Lebert has so well described.

The thermometry of the "active third stage" shows greater extremes than that of any other, and includes both the highest and the lowest ${ }^{1}$ temperatures, the actual maximum being $104 \cdot 6^{\circ}$, the minimum $93 \cdot 6^{\circ}$, a range of 11 degrees! The existence of these extremes, the marked pyrexia, and the subsequent collapse, show a close approximation to the thermal course, as far as we know it, of suppuration and of pyæmia.

Let us briefly summarise the results of the third stage active, as shown in Table IV (see page 96).

1 Since this paper was read I have had under my care a case of this class where the temperature twice fell to $91 \cdot 6^{\circ}$. 


\begin{tabular}{|c|c|}
\hline א & ㅇ \\
\hline 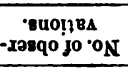 & 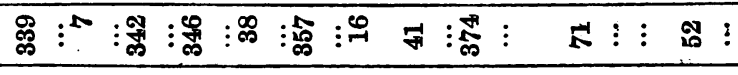 \\
\hline 'mnugutu! & 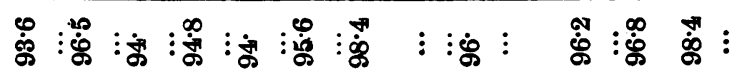 \\
\hline वвә & 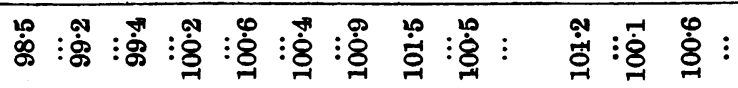 \\
\hline 'mnu!rse & 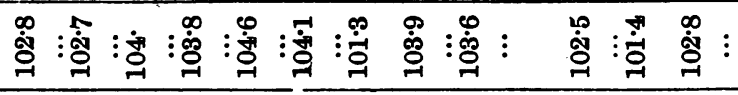 \\
\hline 莺递 & 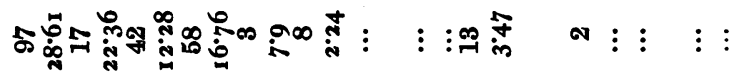 \\
\hline 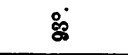 & 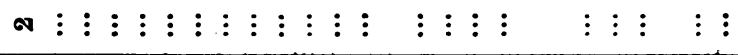 \\
\hline$\stackrel{\circ}{\circ}$ & 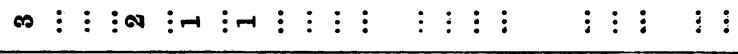 \\
\hline$\stackrel{\circ}{\circ}$ & 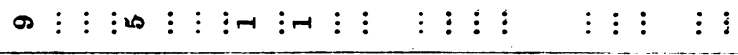 \\
\hline ळ & 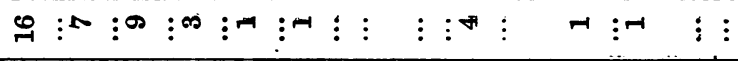 \\
\hline §̊̊ & 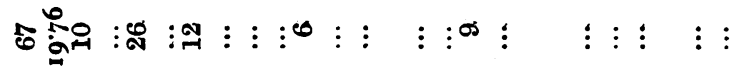 \\
\hline$\varrho_{\infty}^{2}$ & สื่: \\
\hline$\$$ & 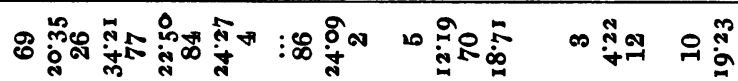 \\
\hline 旁 & 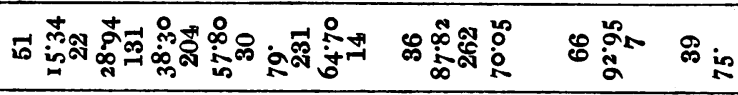 \\
\hline ક્త్రి & ஜ \\
\hline$\stackrel{\circ}{\Xi}$ & 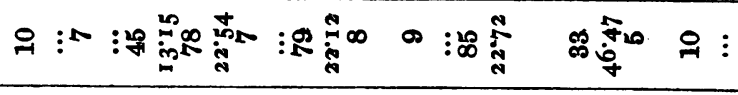 \\
\hline g. & 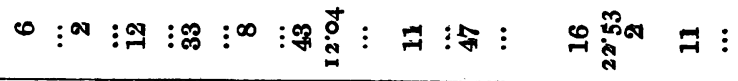 \\
\hline 品 & 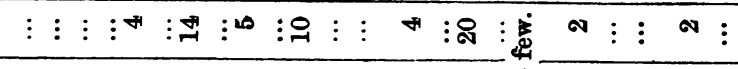 \\
\hline 迥 & 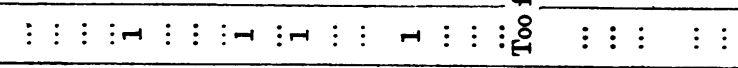 \\
\hline 衰 & 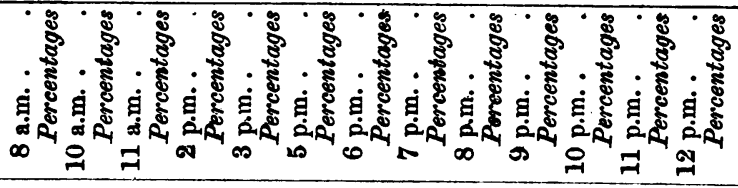 \\
\hline
\end{tabular}


The cases were 43 , and observations were taken 13 times a day, viz., at $8,10,11$ a.m.; 2, 3, 5, 6, 7, 8, 9, 10, 11, and 12 p.m., between 300 and 400 being taken at $8,11,2,5$ and 8 . At 8 a.m., the majority of the temperatures are normal and subnormal; 36 per cent. were between $98^{\circ}$ and $99^{\circ}$, and $28 \frac{1}{2}$ per cent. below $98^{\circ}$, the minimum being $93 \cdot 6^{\circ}$, the maximum $102^{\circ}$, and the mean $99.5^{\circ} ; 20$ per cent. were between $99^{\circ}$ and $100^{\circ}$, and only 15 per cent. above $100^{\circ}$. In the few cases in which $100^{\circ}$ was reached or exceeded, one was accompanied by acute ulceration of the larynx, another by rapid tuberculosis of the opposite lung. Even here a low morning temperature occurred, which was detected at 5 o'clock in the morning, but did not last until 8 , the rise commencing early.

A third exceptional case was one where large hæmoptysis induced catarrhal pneumonia, and subseqnently death. Thus are explained to some extent those isolated high temperatures among a great majority of normal or subnormal ones.

The rise, however, in this stage begins early, and at 10 o'clock 29 per cent. exceed $100^{\circ}, 34$ per cent. exceed $99^{\circ}$; while those under $98^{\circ}$ are 22 per cent.

At 11,38 per cent. are above $100^{\circ}, 1$ reaching $104^{\circ}$; 13 per cent. exceed $101^{\circ}$, while only 12 per cent. remain below $98^{\circ}$, the mean being $99 \cdot 4^{\circ}$. The rise continues through the 2 p.m. records. Nearly 58 per cent. exceed $100^{\circ}$, $22 \frac{1}{2}$ per cent. $101^{\circ}$. The observations at 3 show a persistent rise : at 5 the percentage above $100^{\circ}$ is 64 , i.e. two thirds of the whole number, the maximum being $104 \cdot 1^{\circ}$, the mean $100 \cdot 4^{\circ}$; the minimum $95^{\circ}$. Only $2 \frac{1}{4}$ per cent. fall below $98^{\circ}$.

The high temperatures are continued at 6 and 7 , and at 8 p.m. we find 70 per cent. exceed $100^{\circ}$, and $22 \frac{3}{4}$ per cent. exceed $101^{\circ}$, while only $3 \frac{1}{2}$ per cent. fall below $98^{\circ}$, the mean being $100 \cdot 5^{\circ}$.

The notes at 10 p.m. show the highest temperature, but at the same time a tendency towards equalisation appears, 93 per cent. exceed $100^{\circ}$, the majority ranging between $99^{\circ}$ vol. LVIII. 
and $102^{\circ}$, only one observation falling below $99^{\circ}$. The mean is $101 \cdot 2^{\circ}$.

The 11 and 12 p.m. notes indicate a subsidence, and to still more marked avoidance of extreme pyrexia or collapse. The mean at 12 is $100 \cdot 6^{\circ}$.

The average maximum of the 43 patients was reached at 10 o'clock p.m. ; but this is not invariably the case, for it may be arrived at at any hour between 5 and 10 p.m., and in isolated observations it has been reached even earlier, as will be seen in some of my twenty-four-hour cases.

This is of no great consequence, as the temperature having once risen, often remains for several hours pyrexial in character, but the point of importance is to ascertain the commencement of the rise and of the fall.

Before we quit the day temperature of this class, I venture to exhibit an interesting record of one of these cases taken thirteen times a day, from 8 a.m. to 8 p.m. for a period of eight days, which shows the general temperature course remarkably well, though the rise is somewhat earlier than in the majority of patients.

It was carefully carried out for me by Mr. M'Kinlay, on one of Dr. Symes Thompson's patients, who had a cavity in one lung and fresh tuberculization taking place in both lungs (see Plate II).

George B-, æt. 22, admitted into Richmond Ward under the care of Dr. Symes Thompson, January 14th, 1873.

History. - Cough commenced one year ago, with emaciation and large muco-purulent expectoration. Six months ago symptoms became worse, and occasional diarrhœa occurred. Cough worse at night, accompanied by dyspnœa; skin hot; night sweats considerable; appetite bad; tongue irritable; bowels regular; pulse 128; respirations 28.

Physical signs. $-L$. Cracked-pot sound and flattening to the fourth rib; dry cavernous sounds to the third rib; crepitation posteriorly, most marked at base.

$R$. Crepitation above the scapula, and from the clavicle to the second rib. 
During the period these temperatures were taken, although, as will be seen by the chart, a considerable amount of pyrexia prevailed, he gained weight (see Plate II).

Plate IV shows pretty fully the temperature-course of this important class of cases.

The black dotted line (Plate IV, fig. 1, No. 1) gives the averages of the 43 patients, during the nine periods of the day already mentioned, viz., from 8 a.m. to 12 p.m. The thick black continuous line (No. 2) is a twenty-four hours' cycle of one of these cases, the same of which the eight-day series of temperatures have been exhibited in Plate II. The toothed line (No. 3) is an average of 7 similar cases taken hourly for twenty-four hours, and, like all averages, is not quite so striking as a single case.

A glance at these curves must convince the most sceptical that the pyrexia follows a definite order and law. The general form of the line representing the mean of a large number of daily observations tallies with similar periods in a twenty-four-hours' round of one of these cases; and if further proof were wanting of the close correspondence, it is found in the average of 7 other twenty-four-hour cases.

The rise and fall are well marked in all, though the maximum is not always reached at the same time. The black dotted curve (Plate IV, fig. 1, No. 1) reaches it at 10 p.m.: the toothed line (No. 3), or the average of 7 cases at 8 p.m., and the black continuous line (No. 2), at 6 p.m. When once reached, a fall, for the most part unbroken, takes place, extending through the night into the early hours of the morning, reaching $95^{\circ}$ and even lower temperatures, and the effects of this we see in our low 8-o'clock observations, which are often normal or subnormal.

My colleague Dr. Symes Thompson, on my noticing this to him, suggested that these low temperatures might be owing to the axilla not being properly closed, and suggested my trying the mouth. I have done so in one twenty-four hours' case, and depicted it by the thin line (Plate IV, fig. 1, No. 4)). The general features of this curve are the same, the gradual ascent from the normal fall to the maximum of 
$101.9^{\circ}$ (reached a little earlier than in the axilla cases) the rapid ascent with a few slight interruptions to the minimum $96.4^{\circ}$ reached at 7 a.m., and then the recovery as the day advances. The general characteristics of "third stage active" temperatures may be summed up:-lst. Afternoon and evening pyrexia; 2nd. Rapid fall during night, and early morning; 3rd. Recovery in the later morning hours, and consequent normal temperatures.

The class of third stage quiescent or chronic cavity (Plate IV, fig. 2) is one of the commonest met with in practice, and has for its distinguishing thermometrical feature a remarkably low temperature course. The range of subnormal temperatures is very striking, and will be exhibited in the following case (Case 9), where cavities existed in both lungs, but no extension of disease took place, and some weight was gained. The temperatures ranged from $95.8^{\circ}$ to $98.4^{\circ}$, and the mean temperatures are all below $98^{\circ}$, the 8 o'clock mean being $966^{\circ}$.

CASE 9.-C. J- (Phthisis, III, with subnormal temperatures).

\begin{tabular}{|c|c|c|c|c|c|c|}
\hline & 8 a.m. & 11 a.nı. & 2 p.m. & 5 p.m. & 8 p.m. & Plyysical signs. \\
\hline 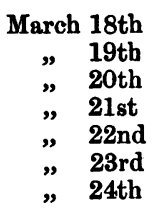 & $\begin{array}{l}96 \cdot 4 \\
96 \cdot \\
96 \cdot 2 \\
97 \cdot 4 \\
96 \cdot 8 \\
97 \cdot \\
96 \cdot 8\end{array}$ & $\begin{array}{l}97 \cdot 2 \\
97 \cdot 8 \\
96 \cdot 6 \\
97 \cdot 4 \\
98 \cdot 2 \\
97 \cdot 2 \\
97 \cdot\end{array}$ & $\begin{array}{l}97 \cdot 8 \\
97 \cdot 2 \\
97 \cdot 4 \\
97 \cdot 8 \\
96 \cdot 8 \\
97 \cdot 6 \\
95 \cdot 8\end{array}$ & $\begin{array}{l}97 \cdot 6 \\
97 \cdot \\
98 \cdot 4 \\
97 \cdot 8 \\
98 \cdot 2 \\
98 \cdot 4 \\
98 \cdot 2\end{array}$ & $\begin{array}{l}98 \cdot \\
98 \cdot 4 \\
97 \cdot 2 \\
98 \cdot 2 \\
97 \cdot 6 \\
97 \cdot 6 \\
98 \cdot\end{array}$ & $\begin{array}{l}\text { Cavernous sounds in } \\
\text { both lungs. }\end{array}$ \\
\hline Average . & $96 \cdot 6$ & $97 \cdot 3$ & $97 \cdot 2$ & $97 \cdot 9$ & $97 \cdot 6$ & \\
\hline
\end{tabular}

The observations on the "third stage quiescent" class were made on twenty patients, five and six times a day. About 150 are recorded at each period. Table $V$ (on p. 101) shows an analysis of them.

Of the 8 a.m. temperatures only $6 \frac{8}{4}$ per cent. reach $99^{\circ}$; 
PHTHISIS PULMONALIS.

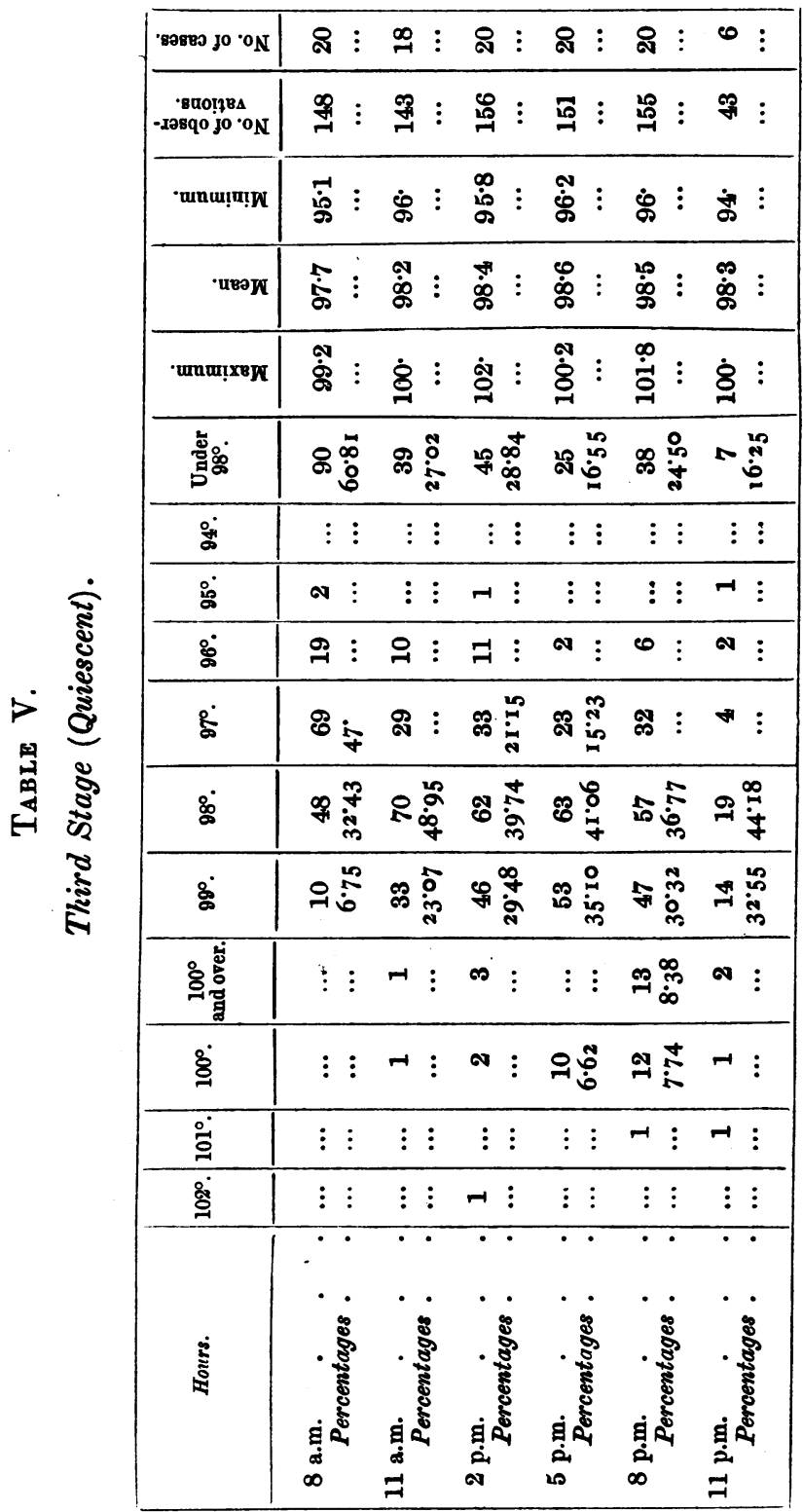


$32 \frac{1}{2}$ per cent. reach $98^{\circ}$; while 60 per cent. fall below it; the minimum being $95^{\circ}$, the mean is $97 \cdot 7^{\circ}$.

A few observations taken at 10 a.m. shows no marked change.

The 11 a.m. notes indicate a slight rise; 23 per cent. reached $99^{\circ}, 49$ per cent. $98^{\circ} ; 40$ per cent. fell below it; the mean being $98 \cdot 2^{\circ}$.

The 2 p.m. notes are slightly higher, and in a few exceptional cases exceed $100^{\circ}$; the mean is $98.4^{\circ}$.

At 5 p.m. the maximum is reached; 35 per cent. exceed $99^{\circ}$, and 16 per cent. fell below $98^{\circ}$, the mean being $98 \cdot 6^{\circ}$.

After this there is a slight subsidence, and at 11 p.m. the mean is $98.3^{\circ}$. The black dotted line in the diagram (Plate IV, fig. 2, No. 1) represents the mean of twenty cases and shows the tendency of this class towards a subnormal character; the mean temperature of these twenty patients hardly reaching the normal $98 \cdot 6$.

The thick continuous line (No. 2) is that of the twentyfour-hours' cycle of a case in this category, which exhibits in addition to the above features a slight afternoon rise, somewhat resembling that of the active 3rd stage, though far less marked. As usually in phthisis, the morning fall is present.

Having thus reviewed the thermal features of these cases, as represented by the statistics, illustrative cases, tables and charts, two main facts stand out regarding consumption generally :

1st. The post-meridian character of the pyrexia when pyrexia exists at all.

2ndly. The remarkable fall at night and the subnormal temperatures of the early morning. ${ }^{1}$

1 At the time when this paper was written I was not cognisant of Surgeon Nathaniel Alcock's (Army Medical Department) very able essay 'On the Nature and Varieties of Destructive Lung Disease, included under the head of Consumption, as seen among Soldiers,' which contains some excellent observations and deductions on the temperature of phthisis. He holds that the " earliest and most appreciable sign is an inability on the part of the person in whom the requirements for the development of tubercle exist, and are about to be set in motion, to maintain the temperature of the body up to the normal standard," and "that long after the deposit has taken place diminu- 
The relations which these bear to a normal standard it is obviously of great importance to ascertain, especially whether or no the fall is peculiar to disease; and for this purpose $I$ have consulted various authorities in order to arrive at that difficult problem, viz. the diurnal thermic course in a healthy man. ${ }^{1}$

Dr. Wm. Ogle's ${ }^{2}$ careful experiments give some clue, but from ranges of hours and not exact periods being given they are hardly suitable for a chart. I have availed myself of Dr. Parkes' standard, 3 agreeing in the main with Dr. Ogle's, and used for testing the effects of

tion of temperature below the normal standard is frequently present during the intervals of local quiescence." He gives several well-marked cases of low temperatures in phthisis, and in some, readings of $96^{\circ} \mathrm{F}$. and $97^{\circ}$ were very common.

My colleague Dr. Pollock made a number of observations on cases of phthisis about the same time that mine were being carried on, and his conclusions, as stated in his lectures at the Brompton Hospital ('Med. Times and Gazette,' July 25th, 1874) were that “ in ordinary quiescent phthisis (stage not specified) the minimum temperature, $98^{\circ}$ or $97^{\circ}$, is in the early morning (3 to 7 ), and the higher temperature occurs from about 3 to 7 in the afternoon."

1 Dr. Jürgensen, of Keil, has made a number of hourly observations on the day and night temperatures of healthy men, extending over several days. These give a chart slightly differing from the annexed one (Plate IV, fig. 2, No. 3), which I prefer to retain, becauge it is as well in comparing standurds to aim at as nearly similar conditions as possible, and the fact of Mr. Kelly being under the same atmospheric conditions as the consumptive patients, and like Dr. Parkes' soldier, of the same nationality, renders the experiment more complete.

Dr. Jürgensen made some interesting experiments of the effects of food and starvation on normal temperatures. The experiment of starvation was carried out ruthlessly, for the man was not allowed even water for thirty-three hours. Slight diminution of the temperature, varying in amount from $\cdot 15$ Centig. to -2 Centig. followed, but the general course and fluctuations were maintained. On food being largely taken the temperature rose to the normal (' Die Korpe Wärme des gesunden Menschen,' 1873).

Dr. Finlayson (' Glasgow Medical Journal,' February, 1869) made a number of hourly observations on healthy children, but the temperature course in these differs so much from that of adults as to be useless for the purposes of this paper.

2 'St. George's Hospital Reports,' vol. i.

3 ' Proceedings of Royal Society,' 1872. 
exercise and alcohol on the body. The observations were carried out on a healthy young soldier, aged 30 , of powerful muscular frame, and were taken every two hours from $8 \mathrm{a.m}$. to 8 p.m.; the figures representing the average of six days. Dr. Parkes' observations extend no further than the day, and being at a loss for a standard of healthy night temperatures, with which to compare the subnormal ones of phthisis, I requested $\mathrm{Mr}$. Kelly, a clinical assistant at the Brompton Hospital, and a remarkably robust young man, aged 22, to submit himself to experiment. He kindly consented, and was therefore put in a bed in a private ward in the hospital, under the same equable temperature conditions as the patients, at 8 p.m., and remained there till 8 a.m. on the following morning, his axilla temperature being hourly observed by Messrs. Parry and Bernays. Beyond a glass of beer at 12 p.m. and some milk at 3 a.m. he had no food and slept soundly a great part of the night, notwithstanding temperature observations being regularly taken. The heat of the ward varied from $62^{\circ}$ to $65^{\circ}$, and he perspired a good deal. Mr. Kelly's night temperatures, combined with Parkes' day records, are shown in the chart (Plate IV, fig. 2, No. 3). It proves that no special fall occurs at night, and therefore we may conclude that the fall in phthisis is abnormal and probably characteristic of consumptive disease.

To what is it due?

I first thought that it might be owing to night sweats, but on carefully consulting my night records, I detected signs of the fall where the skin continued hot and dry, and no perspiration existed. Again, profuse sweats occurred in the afternoon and evening in some instances, while the temperature remained the same. On the whole, there is a greater lowering in patients with night sweats than in those without this symptom, but as I am still pursuing my investigations on this point I will refrain from expressing any decided opinion.

Sleep does not appear to have much effect, as the temperature will sink to $95^{\circ}$ or $96^{\circ}$, even if the patient remains awake, and as regards the effect of want of food and stimu- 
lants, experiments of feeding these patients at night are not yet complete.

In ail cases of phthisis two principal agencies appear to determine the temperature course :

1st. An excessive action of the natural processes by which the body heat is maintained.

2nd. The influence of collapse proceeding from the wellmarked weakening of the constitutional powers in phthisis.

These two agencies are continually struggling for the mastery, and the result of this conflict is the temperature course of the disease. The influence of the first is seen in the rise in the afternoon and evening, well marked in the active forms of all three stages, and regularly recurring day after day, for long periods; the influence of the second is shown in the rapid nocturnal fall and the low temperatures of early morning; the collapse influence is also seen in the subnormal day temperatures occasionally occurring in all stages of the disease, and even where the active processes of lung tuberculization, of softening, and of excavation, may be taking place. It is, however, chiefly noted in the quiescent forms of the first and third stages.

When low temperatures accompany lung tuberculization or excavation, it is probable that the collapse influence is greater than the pyrexial, and therefore masks it.

Where the chart shows occasional fitful variations, these agencies are, perhaps, evenly balanced, and may alternately prevail, as is witnessed in the end.temperatures of consumption; and to these deviations noticed in advanced cases may be ascribed the prevailing and erroneous opinion that phthisis has no definite temperature course.

Dr. Burdon Sanderson mentioned to me an experiment which bears on this subject. He inoculated a guinea-pig and a dog with an equal quantity of purulent liquid. The temperature observations were then taken on both animals, and showed a lowering of temperature in the guinea-pig, and a considerable rise in the $\operatorname{dog}$; the poison, therefore, produced pyrexia in the stronger animal, and collapse in the weaker one. 


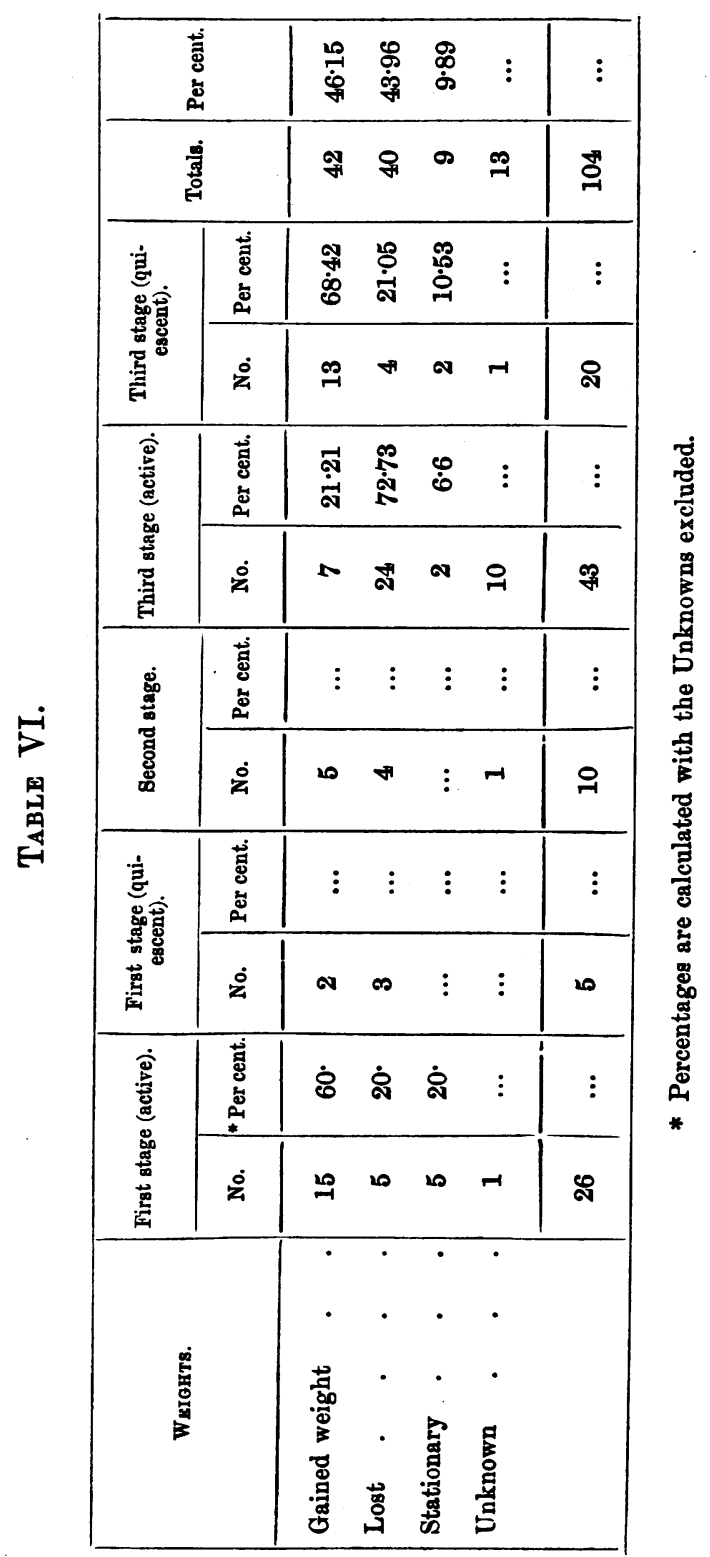


The weights of the greater number of these patients have been taken before and after the thermometric observations, and the following table gives the result, and will, I think, repay a study as bearing upon the influence of pyrexia on weight (see Table VI, p. 106).

The thirteen unknowns are excluded, in calculating the percentages, but it is doubtful whether they ought not to be included among the losers, as the reason that the weight was not taken was generally that the patients were too ill to leave their beds.

We see that out of 91,42 gained weight, 40 lost, and 9 remained stationary.

Of the first stage, active, 60 per cent. gained, 20 per cent. were stationary, and 20 per cent. lost.

In the second stage half of the patients gained weight.

The greatest loss is, as might be expected, in the third stage, active, where 72 per cent. lost weight; but even here 31 per cent. gained, and when we consider the desperate character of some of the cases, and their collapsed condition, how pyrexia continued in many for weeks and months, it is remarkable that so large a number did not lose weight.

The largest number of gainers is in the " third stage quiescent," where the percentage is 68 ; 10 per cent. were stationary, and 21 per cent. lost, and considering the number of double cavity cases this is noteworthy.

The reason of the large proportion of gain lies in the amount of food taken, combined with rest and comfort.

The quantity of food eaten by even those patients whose appetites are capricious is very considerable, owing to the regular stuffing system of the Brompton Hospital, and the number of delicacies supplied to meet every fancy. The scales often discover a gain in the weight of patients in whom it could have least been predicted.

The deductions from this table are-

1st. That, though the tendency of the disease is towards emaciation, gain of weight is possible in every stage, provided there be no diarrhœa or hæmoptysis, and that food can be taken and assimilated. 
2nd. That pyrexia is not incompatible with gain of weight provided the appetite be good.

3rd. That while active third-stage cases are the least likely to gain weight, chronic cavity patients are the most likely to increase in flesh.

4th. That neither tuberculization nor softening preclude gain of weight.

These conclusions will be found in direct opposition to Niemeyer," who states that he made out by " numberless examinations, with a thermometer and the weighing machine, that the decrease and increase in the weight of phthisical patients are respectively in relation to the height of the fever or to its disappearance;" but they confirm Dr. Ringer's" remark that "patients with a very considerable elevation of temperature, but who enjoy a good appetite do not lose flesh, provided always they are not employed in any active pursuit which entails much waste of tissue."

The influence of the various phthisical phenomena such as diarrhœa, hæmoptysis, pneumothorax, ulceration of the larynx and intestines, and albuminuria as also the effects of the contraction of cavities are postponed for a future communication.

1 'Text Book of Practical Medicine.'

2 Op. cit. 


\section{DESCRIPTION OF PLATES II, III, AND IV.}

\section{Phate II.}

Case of George B-, aged 22. Temperature chart of his case, being a record of temperature taken thirteen times a day, from 8 a.m. to 8 p.m., for a period of eight days (see page 98 ).

\section{Plate III.}

FrG. 1.-Phthisis, Stage I, active.

No. 1 (black dotted line).-A verages of 26 patients during seven periods of the day from 8 a.m. to 12 p.m. (see page 81 ).

No. 2 (thick black continuous line).-Twenty-four hours' cycle of one case (see page 81).

Fig. 2.-Stage I, quiescent, and Stage II.

No. 1 (black dotted line).-Average of five cases of Stage I, quiescent (see page 82).

No. 2 (thick black continuous line).-Twenty-four hours' cycle of one case (see page 83).

No. 3 (open crossed dotted line).-Average of ten II Stage cases (see pages 83,87 ).

\section{Plate IV.}

FIG. 1.-“"Stage III, active."

No. 1 (black dotted line).-Averages of 43 patients during nine periods of the day from 8 a.m. to 12 p.m. (see pages 89 , 99).

No. 2 (thick black continuous line). - Twenty-four hours' cycle of one of the 43 cases [the case of George B-, depicted also in Plate II], (see page 99).

No. 3 (toothed line).-Average of twenty-four hours' cycle of seven similar cases (see page 99 ).

No. 4 (thin continuous line).- Single case of temperature taken in the mouth (see page 100).

FIG. 2.- "Stage III, quiescent" and " normal" (page 100).

No. 1 (black dotted line).-Average of 20 cases taken eight times a day (see page 102).

No. 2 (thick black continuous line).-Twenty-four hours' cycle of one case (see page 102).

No. 3 (thin continuous line).-Twenty-four hours' cycle of normal temperature, (see page 104). 
Plate II.

Med.Chir.Trans.Vol LVIII

GEORGE B :......AGE 22.

TEMPERATURE TAKEN IN THE AXILLA.

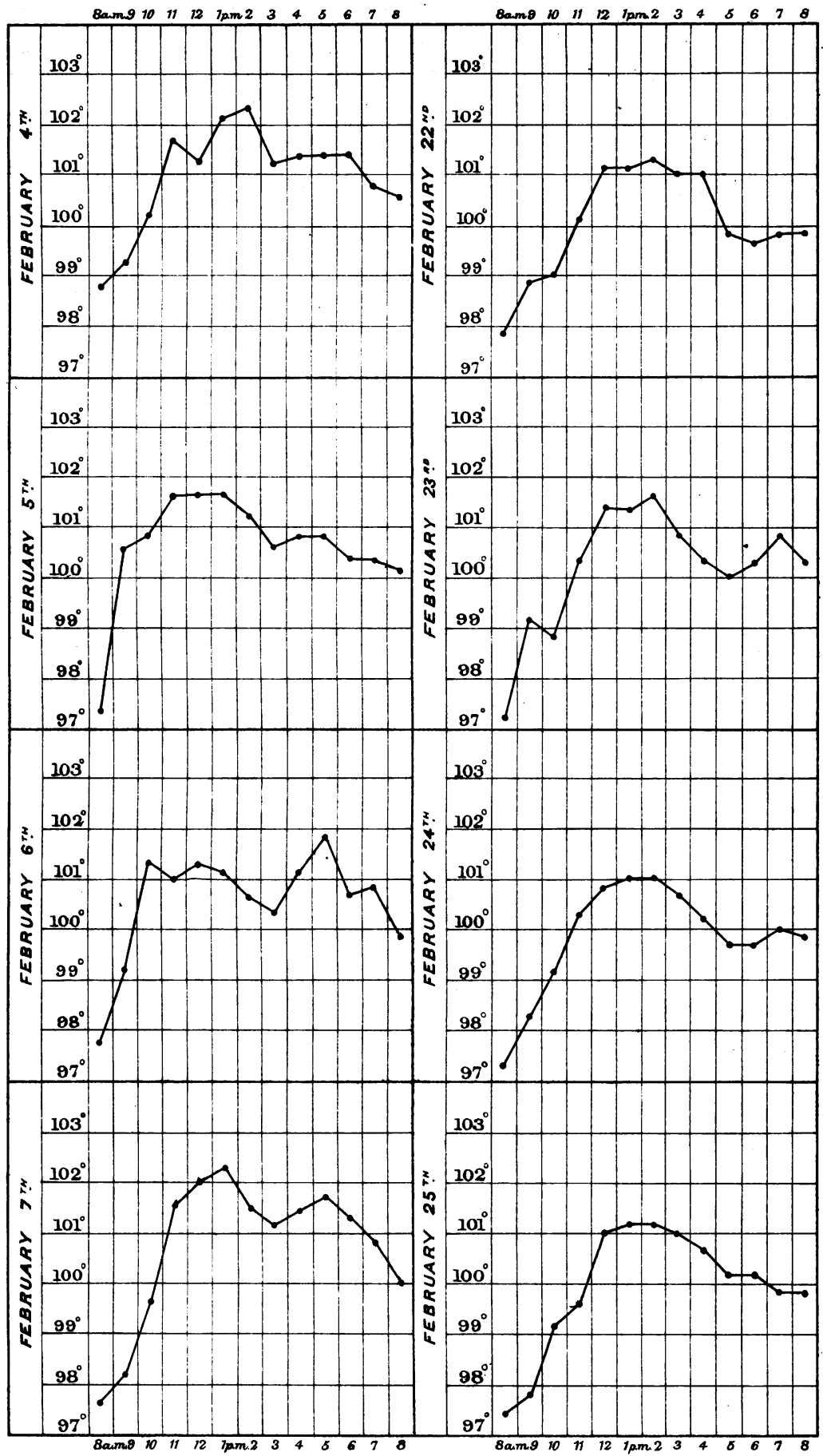

Mintern Bros . lith. 


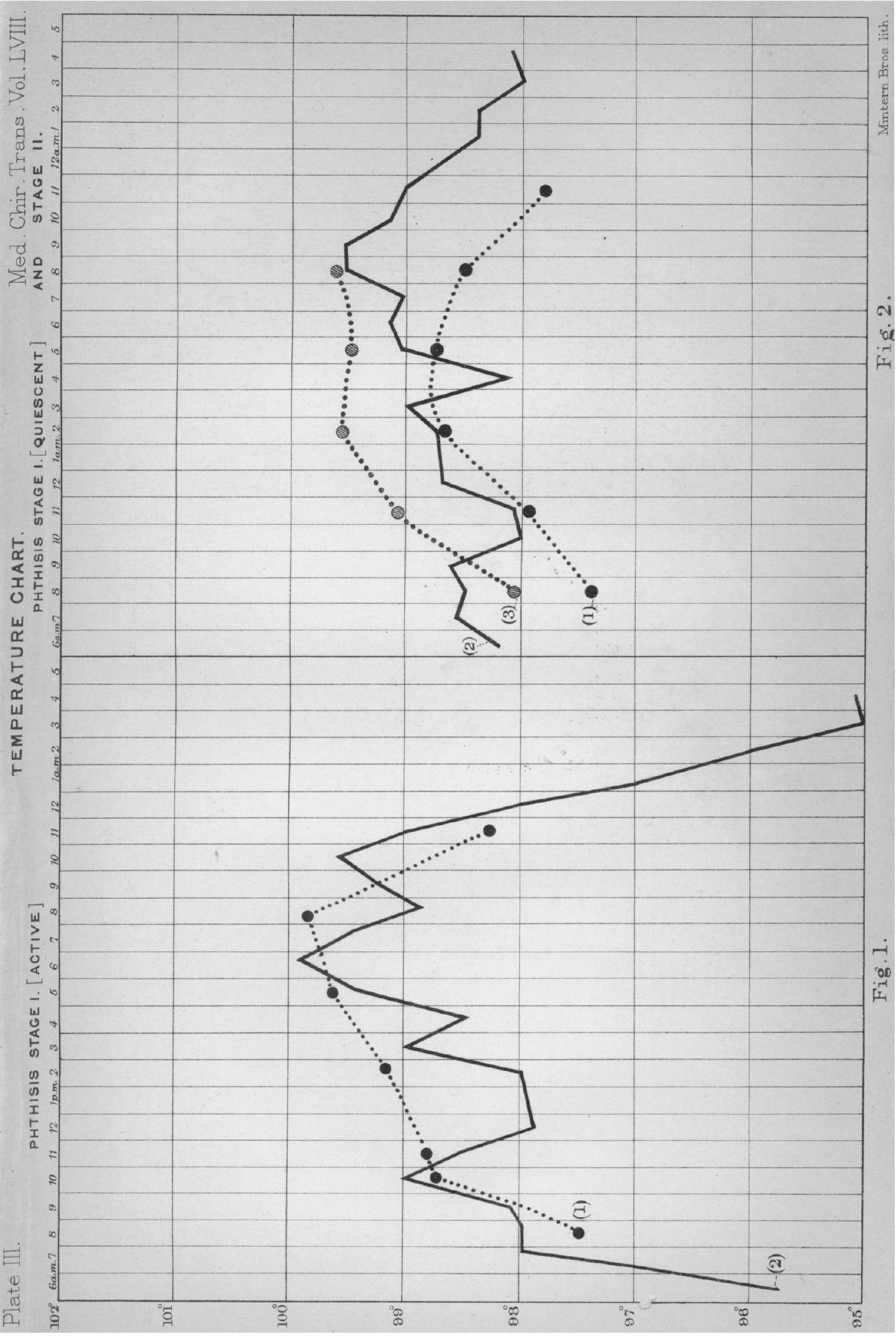




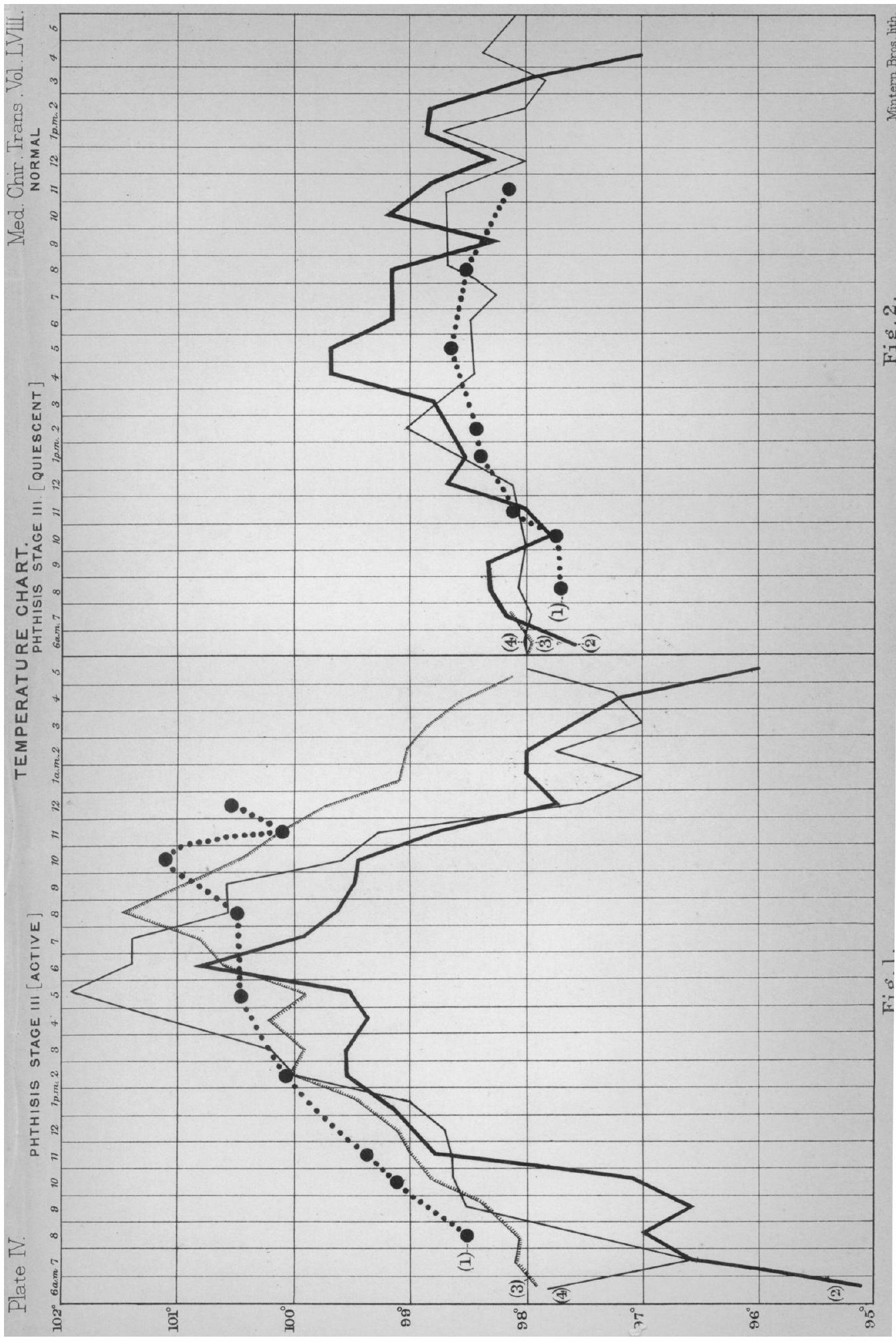

